Max Marwede, Armin Reller

\title{
Future recycling flows of tellurium from cadmium telluride photovoltaic waste
}

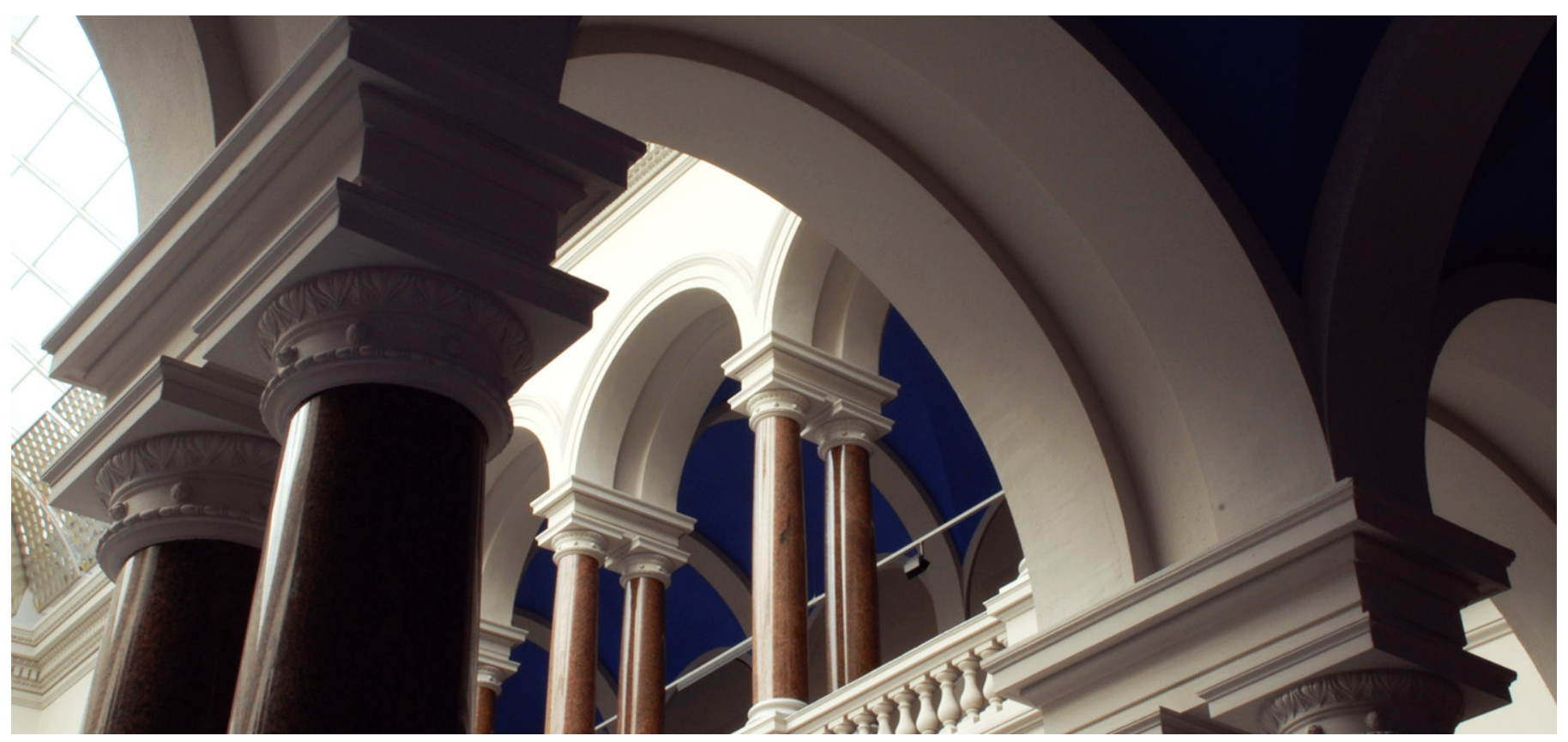

\section{Suggested Citation}

Marwede, Max; Reller, Armin: Future recycling flows of tellurium from cadmium telluride photovoltaic waste. - In: Resources, Conservation and Recycling. - ISSN: 0921-3449. - 69 (2012), December. - pp. 35-49. (Postprint Version is cited, page numbers may differ. The final publication is available at DOI: 10.1016/j.resconrec.2012.09.003.) 


\section{Introduction}

According to the European Photovoltaic Industry Association (EPIA), photovoltaic energy has the potential to contribute up to $12.6 \%$ to the global electricity supply by 2040 (EPIA, 2011). Previously, crystalline silicon photovoltaic (c-Si PV) technologies have been the dominant technology with market share of $86 \%$ in 2010 . The remaining $14 \%$ was allocated to other PV technologies, including inorganic thin-film technologies. Of these emerging technologies, thin-film cadmium telluride photovoltaics (CdTe-PV) make up approximately $40 \%$ (Hering, 2011), with very low production costs of 0.75 US-Dollar per watt peak (First Solar, 2011a). The market leader First Solar accounts for almost all sales of this technology by supporting a production capacity of $1.5 \mathrm{GW}$ in 2010 (First Solar, 2011a). However, there are two major concerns about this PV technology: On the one hand, the potential negative environmental impacts of $\mathrm{Cd}$ contamination from CdTe-PV, and on the other hand, a possible shortage of the metal Tellurium (Te).

The fear of Cd emissions from CdTe-PV modules during their life cycle could be largely invalidated; previous research shows that the life-cycle $\mathrm{Cd}$ emissions from CdTe-PV are one to three orders of magnitude below the Cd emissions of other forms of electricity generation (Fthenakis, 2004; Fthenakis et al., 2008). Based on these facts, Raugei and Fthenakis (2010) predicted various scenarios of worldwide Cd emissions in 2050 caused by CdTe-PV and compared them to current Cd flows in Europe. The study indicates that an expanding CdTe-PV sector will reduce, rather than increase, the amount of cadmium-related environmental pollution globally ${ }^{1}$, provided that CdTe-PV modules are recycled (Raugei and Fthenakis, 2010).

Recycling of PV waste is essential, not only to avoid Cd emissions but also to conserve Te; various studies show that accessible Te reserves and annual Te production can, to a certain extent, limit the market growth of CdTePV (Andersson, 2000; Feltrin and Freundlich, 2008; Fthenakis, 2009; Green, 2009; Wadia et al., 2009; Zuser and Rechberger, 2011; Zweibel, 2010). In general, three research methods have been used to reveal limitations. These deal primarily in the estimation of:

1. the maximum annual PV production with refined Te,

2. the maximal cumulative capacity or maximal electricity generation with available Te reserves, and

3. the Te demand as a result of market scenarios.

It is difficult to compare the results because of differing assumptions about available reserves, (future) Te production, market developments and material demand per watt peak $\left(W_{p}\right)$. Of course, it is to be expected that these values change over time due to economic and technological developments. Recent studies (Candelise et al., 2011; Fthenakis, 2009; Green, 2009; Wadia et al., 2009; Zuser and Rechberger, 2011; Zweibel, 2010) conclude that an absolute shortage of Te is unlikely, but temporary bottlenecks in supply and high prices will be an issue for the CdTe-PV industry. Thus extensive recycling and material efficiency is part of the solution to ease possible constraints.

This paper analyzes the extent to which recycling and efforts to increase material efficiency can lower the demand for primary Te. A dynamic material flow analysis was used to examine how much Te can be recovered in the future from CdTe-PV production and end-of-life scrap, as a substitute for primary material, and how much Te has to be disposed of. Worldwide scenarios projected until 2040 show how material efficiency measures - higher material utilization in production, decrease of material content in PV modules, and recycling of production scrap and end-of-life modules - will affect demand, waste flows, and recycling flows of semiconductor grade Te.

\section{Research process and methods}

Figure 1 depicts the research process undertaken in this study. Key parameters and main processes, which represent the life cycle of a PV module and influence the PV waste flows, were determined via desktop research and personal questionnaire-based interviews with photovoltaic manufacturers, recycling companies, and research institutes. Based on this information, a dynamic material flow system corresponding to the life cycle of a CdTe-PV module was modelled using the material flow analysis software STAN as well as further computation of market developments and lifetime probabilities.

Furthermore, we used the information collected to develop scenarios, which represent different technological trajectories at the product and processing level. These trajectories are described in storylines. The parameters and necessary flows were implemented in the material flow model. The results were analyzed and indicators developed, which describe the efficiency of the system.

\footnotetext{
${ }^{1}$ Because of those arguments PV is still excluded from the European directive on the restriction of the use of certain hazardous substances in electrical and electronic equipment (RoHS).
} 


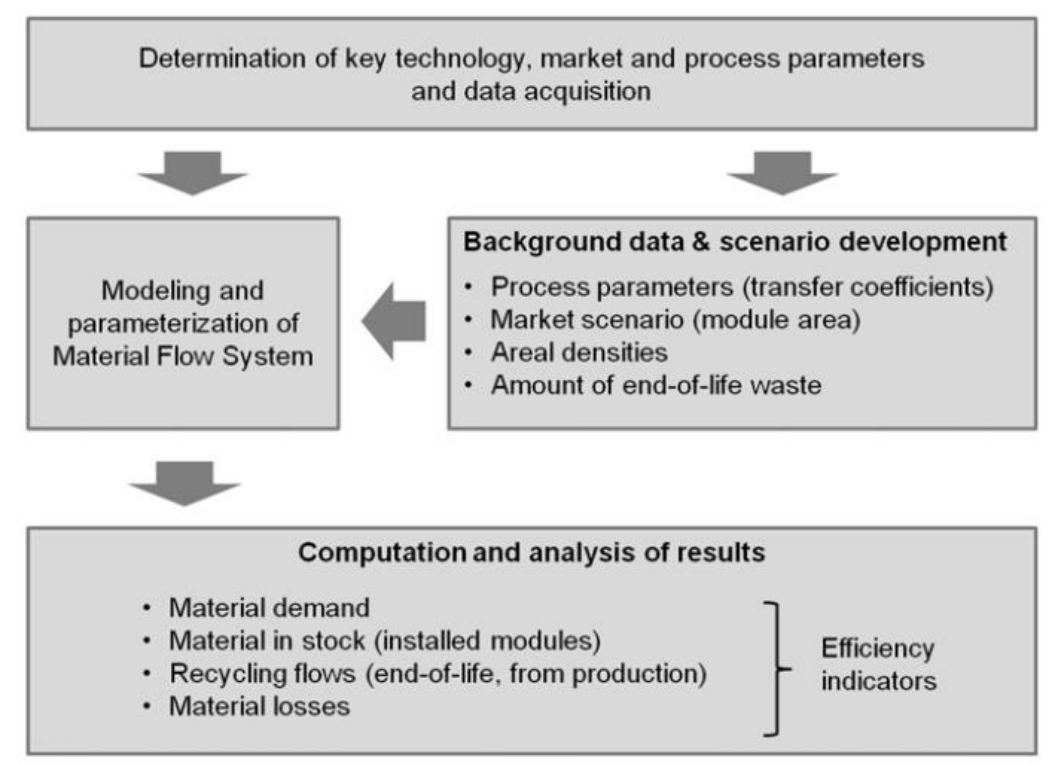

Figure 1 Research process

A material flow analysis (MFA) regards physical material flows of the economy as an industrial metabolism (Ayres, 1989). The most important element of a MFA is the mass balance; it helps to identify unexpected or hidden material flows and inventory in an economy or in the environment (Bouman et al., 2000). A MFA can be used to estimate the material intensity of an economy, but also on a smaller scale to assess recycling systems. It helps to identify influencing factors in recycling flows and opportunities for optimization (Brunner and Ma, 2009). To estimate future material flows the formerly static MFA was modified to a dynamic model (Elshkaki et al., 2005; Kleijn et al., 2000; Melo, 1999).

Within a material flow system, material flows between processes, stocks, and sinks (sinks have no outflow). A process is defined by its transfer coefficients. A transfer coefficient determines which part of an input to a process is transferred to the subsequent process. The mass balance principle demands that the sum of the transfer coefficients for a specific input equals 1 (Brunner and Rechberger, 2004).

The material flow system for CdTe-PV was modelled using the graphical interface of the software STAN (Figure 2 and Figure 3). STAN calculates flows, sinks, and stocks based on formulas found in Cencic and Rechberger (2008). Table 1shows the key flows and process parameters necessary to determine the remaining flows, the stock "installed modules", and the sink "discarded material". The necessary data for the scenario assumptions can be found in Section 3.

\begin{tabular}{|c|c|c|c|}
\hline & & Parameters & Section \\
\hline \multirow[t]{2}{*}{ Flows } & Produced modules & $\begin{array}{l}\text { - Yearly production of CdTe-PV in square meter } \\
\text { - Areal density of Te in CdTe-PV cells }\end{array}$ & $\begin{array}{l}3.1 \\
3.2 \\
\end{array}$ \\
\hline & End-of-life modules & $\begin{array}{l}\text { - Lifetime probability } \\
\text { - Percentage of early returns }\end{array}$ & 3.5 \\
\hline \multirow[t]{4}{*}{$\begin{array}{l}\text { Process } \\
\text { es }\end{array}$} & CdTe-Deposition & $\begin{array}{l}\text { - Material utilization } \\
\text { - Recovery overspray }\end{array}$ & 3.3 \\
\hline & Process line & $\begin{array}{l}\text { - Overall equipment efficiencies } \\
\text { - Percentage of production rejects collected for } \\
\text { recycling }\end{array}$ & 3.4 \\
\hline & Recycling \& Refining & $\begin{array}{l}\text { - Recycling rates } \\
\text { - Refining rates }\end{array}$ & 3.6 \\
\hline & Collection & - Collection quota & 3.7 \\
\hline
\end{tabular}

Table 1 Flows, processes and key parameters to determine waste streams

The following paragraphs describe the processes and formulas used to calculate the key flows of the system. Figure 2 shows the subsystem "production" of the material flow system (Figure 3). A box represents a process and an arrow a flow. Flows are either imported (I) from the system or exported to the system (E), which is shown in Figure 3. Recycled material (flows "recycled material production" and "recycled material EoL") is credited to the feedstock to determine, how much can be substituted by recycled material. The feedstock is 
therefore composed of recovered material from production scrap (off-spec modules and overspray), recovered material from end-of-life modules, and additional material imported from external sources (flow "demand"). In the subsystem, material utilization rates of the CdTe-deposition process and overall equipment efficiencies are the key parameters in determining waste streams. The transfer coefficients of the process "CdTe deposition" define how much of the raw material deposited ends up on the substrate. The remains (overspray) coats the equipment and deposition chamber and has to be removed regularly. The process "recovery" defines how much of this overspray can be transferred to a refinery. The process "module production" represents the overall equipment efficiency of the production line. It determines how many modules, i.e. module area, are rejected during production (off-spec modules). The process "collection" specifies how much of the "off-spec modules" are directed to recycling or are discarded, respectively. Besides overspray and rejected modules, material waste also occurs during edge grinding and scribing of cells and contacts. This amount, however, is neglected in this material flow analysis.

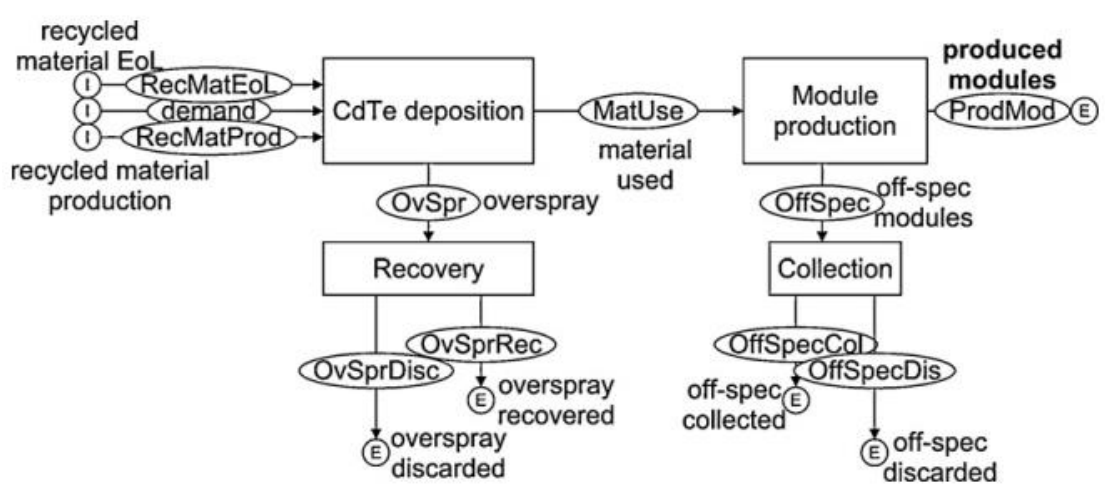

Figure 2 Subsystem production of the material flow system (Figure 3)

To assess the efficiency of the production system, three indicators are used. The indicator "material utilization" specifies how much of the raw material ends up in the final module, i.e. the material bound in produced modules divided by the feedstock. The "material recovery rate" indicates how much of the production scrap (material in rejected modules and excess material from deposition) can be reprocessed into high quality material (semiconductor grade) ${ }^{2}$. Finally, the "scrap rate" can be calculated, which equals the share of discarded material at feedstock.

Subsequent to the parameterization of the processes in the subsystem, the remaining flows in the subsystem can be calculated by STAN after inputting the flow "produced modules" $F^{p m}(a)$, i.e. the amount of material $r$ bound in the produced modules in the year of production $a$. The flow $F^{p m}(a)$ into the stock "installed material" (Figure 3 ) is calculated by inputting the module area $A_{a}$ in year $a$ and assigning an areal density $\mu_{r a}$ to the flow. Note that the area produced is set equal to the area installed in a given year.

$$
F^{p m}(a)=\mu_{r a} \cdot A_{a} \quad \text { Formula } 1
$$

The size of the stock "installed material" is dependent on its inflow $F^{p m}(a)$ and outflow $F^{E O L}(a)$. The material outflow "end-of-life (EoL) modules" of the stock "installed material" is determined by the lifetime of the modules. Some of the modules will be scrapped earlier than average, others later. As statistics on the lifetime of CdTe-PV modules are hard to come by, the lifetime of the modules is computed by using a statistical distribution function $f(t)$. The probability $p_{t}$ of scraping a product with a service life to $t$ years is:

$$
p_{t}=\int_{t}^{t+1} f(\tau) d \tau
$$

Formula 2

The outflow of the stock $F^{E O L}(a)$ in year $a$ (flow "EoL modules" in Figure 3 ) equals the sum of the inflows from previous years multiplied by the probability $p_{t}$ of a product being discarded after $t$ years:

$$
F^{E o L}(a)=\sum_{t=o}^{a} p_{t} \bullet F^{p m}(a-t)
$$

Formula 3

The process "module recycling" determines how much material is recovered during the treatment of off-spec modules and end-of-life modules. In the model, recovered material and production waste from deposition is further purified in a refinery to semiconductor grade material, which is then fed back into the production. The processes "module recycling" and "refinement" appear twice to be able to differentiate the recycling flows.

\footnotetext{
2 Even if cadmium is not recovered for reprocessing to high purity material, it is recovered for environmental and safety reasons and afterwards deposited safely.
} 
The indicator "end-of-life recycling rate" describes the efficiency of the end-of-life recycling chain, and shows how much of the material bound in end-of-life modules is reprocessed to semiconductor grade material.

The sink "discarded material" gathers all the material that cannot be recovered and purified to semiconductor grade material. The boundary of the system is depicted in Figure 3 as a dotted line, which represents that the mining and processing of primary or recycled material coming from sources other than CdTe-PV has not been accounted for.

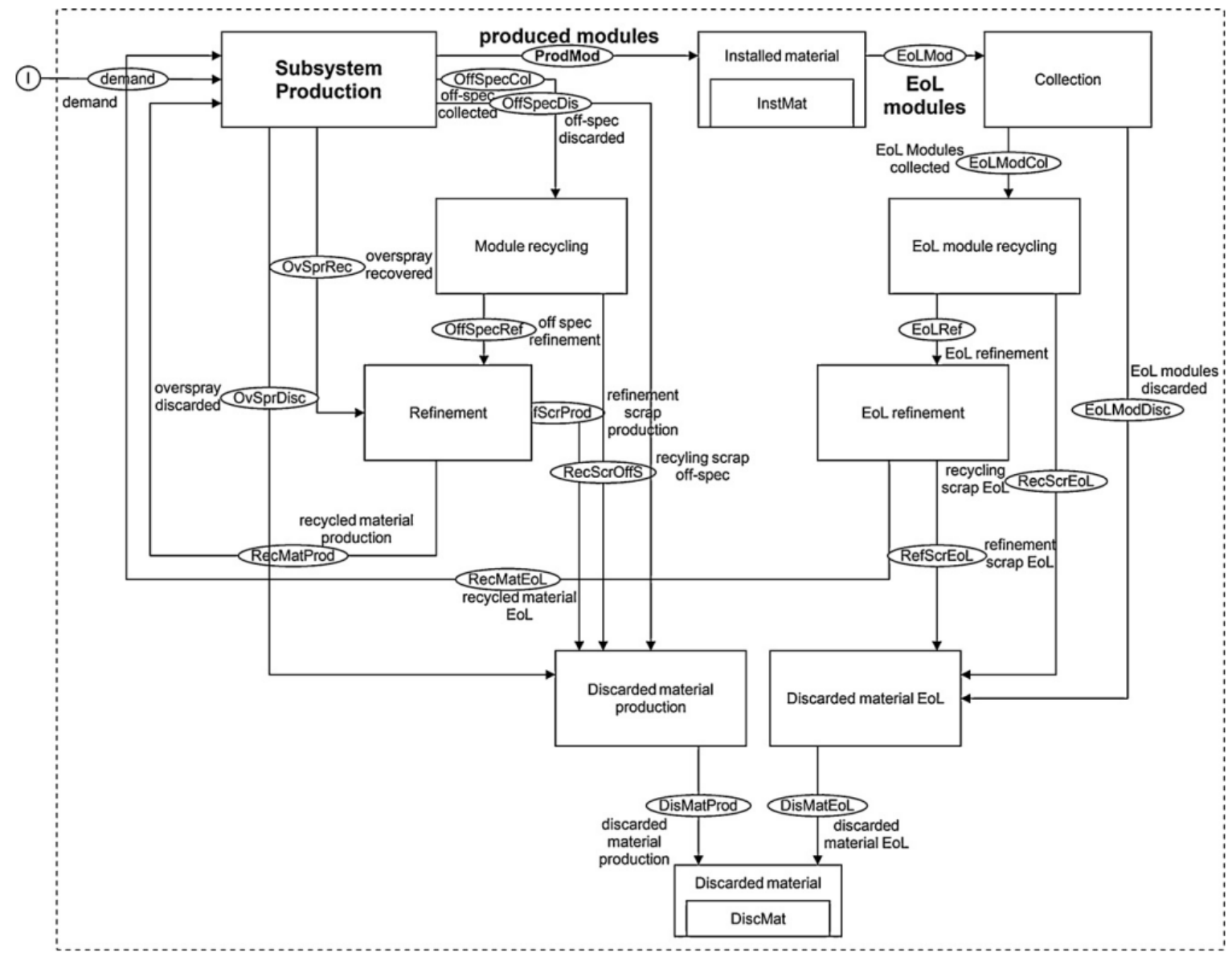

Figure 3 Material flow system for CdTe-PV along the life-cycle

\section{Background data and scenario development}

The following paragraphs present the data necessary to determine the transfer coefficients of the processes in the material flow model described above, and the required data for the formulas. The information is derived from desktop research and personal questionnaire-based interviews with photovoltaic manufacturers, recycling companies, and research institutes. Using this data, three scenarios were developed; hereafter labelled as "breakthrough", "steady advance", and "slow progress" scenario. These scenarios represent different market developments and technological trajectories, more specifically; lifetime expectancies, material efficiency in the production processes and material content of the solar cell, as well as collection quotas and recycling efficiencies. All assumptions are listed in Table 3. The base year of the scenarios is 2010 and global Te flows within the life-cycle of CdTe-PV modules are predicted thirty years into the future.

\subsection{Produced area}

The material bound in produced modules is calculated by multiplying the areal density of Te in the CdTe-cell by the annual area produced (Formula 1). The area produced $A$ in year $a$ is identical to the yearly installed photovoltaic power $C_{a}$ in watt peak $\left(\mathrm{W}_{\mathrm{p}}\right)$ divided by the required area per $\mathrm{W}_{\mathrm{p}}$, which is dependent on the efficiency of the module $\eta_{a}^{3}$ :

$$
A_{a}=C_{a} /\left(I \cdot \eta_{a}\right)
$$

\footnotetext{
${ }^{3}$ Measured at standard test conditions (light intensity $\mathrm{I}=1,000 \mathrm{~W} / \mathrm{m}^{2}$ at $25^{\circ} \mathrm{C}$ )
} 
$C_{a}$ can be taken from a market scenario. Here market scenarios are computed with the use of annual growth rates $(A G R)$ :

$$
C_{a+1}=C_{a} \cdot(1+A G R)
$$

Formula 5

The annual growth rates are taken from the sigmoid function $S(x)=1 /(1+\exp (-x))$ as: $A G R=S(x) / S(x-1)-1$

Formula 6

to model a typical S-formed market growth of a new technology.

In 2010 the market share of CdTe-PV was about $5 \%$ (Hering, 2011). It is typically difficult to make robust assumptions about market shares for the future. Currently, several manufacturers have delayed or abandoned their expansion plans or even close down factories due to the precarious market situation (First Solar, 2012a; pv-magazine, 2012a, 2012b). The scenarios introduced follow the prospective production capacities of the main producers in the near future. We also consider EPIA's prediction that CdTe-PV will have a market share of over $10 \%$ by 2020 (EPIA, 2011). Furthermore it's assumed that the CdTe-PV market share shrinks from 2020 onwards, i.e., the CdTe-PV market will grow slower than the overall market (sigmoid growths), as emerging technologies will enter the market. Considering these criterions, annual growth rates (AGR) are calculated to reach an annual CdTe-PV production capacity of $4 \mathrm{GW}_{\mathrm{p}}$ in the "slow progress" scenario (market share: $2.5 \%$ ), $8.1 \mathrm{GW}_{\mathrm{p}}$ in the "steady advance" scenario (market share: $5 \%$ ), and $12.2 \mathrm{GW}_{\mathrm{p}}$ in the "breakthrough" scenario (market share: $7.5 \%$ ).

The conversion efficiency of the modules determines the area produced each year. First Solar (2011a) reported in 2010 a $0.5 \%$ annual improvement of PV module conversion efficiency, ultimately amounting to $11.6 \%$ by the end of 2010. Wadia et al. (2008) calculated a maximal theoretical conversion efficiency of $33 \%$ for CdTe-PV cells, whereas the generally considered maximum efficiency for CdTe-PV modules is $18 \%$ (Raugei, 2012). Until now, the highest CdTe-PV module efficiency has been confirmed at $14.4 \%$ (First Solar, 2012b), while the highest research-cell efficiency has been confirmed at $16.7 \%$ (Kazmerski, 2011). The technology roadmap of the International Energy Association (IEA) has set a goal for conversion efficiency of $15 \%$ by the year 2030 for commercial CdTe-PV modules (IEA, 2010). Zuser and Rechberger (2011) predict in their scenarios that module conversion efficiencies will reach $15 \%, 16.7 \%$ respectively, by 2040.

Here it is presumed that conversion efficiencies in 2010 are equal to the average of First Solar's modules $(11.3 \%)$ in the same year (First Solar, 2011a). In 2040 module conversion efficiencies are assumed to reach $18 \%$ (breakthrough), $16.5 \%$ (steady advance), and $15 \%$ (slow progress). The required area per watt peak from 2011 to 2039 is interpolated.

\subsection{Areal density}

The areal density $\mu_{r a}$ depends on the thickness of the semiconductor compound layer in year a, its density $\rho$, and the weight percentage $\omega_{\mathrm{r}}$ of material $r$ in the semiconductor compound layer.

$$
\mu_{r a}=d_{a} \cdot \rho \cdot \omega_{r}
$$

In a CdTe solar cell, a cadmium telluride and cadmium-sulphide layer of commonly 2-5 $\mu \mathrm{m}$ form the $\mathrm{p}-\mathrm{n}$ junction (Razykov et al., 2011). The Norwegian Geotechnical Institute (NGI) reports that in 2009 the CdTe-layer thickness of First Solar's module was $2.2 \mu \mathrm{m}$ (NGI, 2010). This value approximates the results of the leaching test conducted by the NGI, yielding a layer thickness of $2.1 \mu \mathrm{m}$ (Green, 2011). Taking into account that not all production in the year 2010 can be attributed to First Solar, layer thicknesses between 2 and $3 \mu \mathrm{m}$ are set in the scenarios. Assuming that the CdTe-layer with a density of $6,200 \mathrm{~kg} / \mathrm{m}^{3}$ is stochiometric, $53 \%$ of its weight is Te.

One possible way to decrease material demand in the future is a thinner active layer. Just $2 \mu \mathrm{m}$ are required to absorb most of the useful part of the solar spectrum (Razykov et al., 2011), $0.44 \mu \mathrm{m}$ to absorb $85 \%$ of available energy equal or larger than the material bandgap (Wadia et al., 2009). In research thickness is reduced below 1 $\mu \mathrm{m}$ (Amin et al., 2007; Jones et al., 2009). To avoid the loss of the spectrum while reducing the thickness, the light can be trapped in the cell by either reflecting the light with a mirror on the backside or bending it when it enters the cell to make the path of the incident light longer (or a combination of both methods). Amorphous silicon cells with about the same absorption coefficient as CdTe are already made with these optical enhancements, with layer thickness ranging between 0.1 to $0.3 \mu \mathrm{m}$ (Zweibel, 2010).

In the "breakthrough" scenario it is assumed that using similar light trapping methods the CdTe-layer thickness can be reduced to $0.1 \mu \mathrm{m}$ by 2040 - from $2 \mu \mathrm{m}$ in 2010. In the "slow progress" scenario the thickness, equalling $3 \mu \mathrm{m}$ in 2010, can't be decreased to less than $2 \mu \mathrm{m}$ because of unacceptable efficiency losses. Finally, in the "steady advance" scenario, a thickness of at least $1 \mu \mathrm{m}$ is required - starting with $2.5 \mu \mathrm{m}$ in 2010.

\subsection{Material utilization}

Measures to reduce material content per watt peak include reducing layer thickness and increasing conversion efficiency. Besides these measures, which occur at module level, improving the material utilization of the 
deposition processes and the overall production efficiency can also reduce the raw material feedstock. Both values are necessary to be able to compute the flows in the "subsystem production" (Figure 2).

Based on available data, Green (2011) estimates that approximately $40 \%$ of the raw material feedstock is used in production. Fthenakis (2009) implicitly assumes a higher utilization rate of about $60 \%$ for 2008 . According to Fthenakis, the current Te demand equals $100 \mathrm{t} / \mathrm{GW}_{\mathrm{p}}$ (personal communication, 05.10.2011). Assuming a material content of $0.06 \mathrm{~g} / \mathrm{W}_{\mathrm{p}}$ (conversion efficiency $11.7 \%$, layer thickness $2 \mu \mathrm{m}$ ), it can be concluded that the material utilization hasn't improved mentionable since 2008. It's not clear, whether the recycling of production waste is already included in these numbers.

How much of the raw material feedstock becomes deposited on the substrate depends on the deposition process. The two leading methods currently in use for the deposition of CdTe-films on substrates are vapour transport deposition of CdTe and CdS powder and electrodeposition of CdTe in combination with chemical surface deposition of CdS (Fthenakis, 2004).

In vapour transport deposition, $\mathrm{CdTe}$ and $\mathrm{CdS}$ are deposited from the compounds in powder after vaporization Typical material efficiency rates range from $50 \%$ to $70 \%$; higher rates are predicted for scaled up production lines (Fthenakis, 2004). In the high-rate vapour transport deposition process of First Solar most of the unused vapour condenses on the reactor's wall, shielding transport belts, etc. Less than $1 \%$ of the vapour is carried out in exhaust streams (Fthenakis, 2004). In another process, atmospheric pressure chemical vapour deposition, most of the non-film generating vapour is released into the exhaust stream, where it can subsequently be filtered out (Johnson NW et.al, 2006).

Part of general maintenance to ensure proper functioning includes the removal of material built-up on the equipment components. Loose material in the chamber can be extracted with an industrial vacuum cleaner. Some components are sandblasted on site; others are treated physically and chemically by a service provider at its respective facility. Usually, physically removed materials are discarded together with the abrasives used for cleaning; less contaminated material may be further processed to recover raw materials. A recovery of the metals found in the filter slurry of the wet-chemical cleaning processes is to-date neither economical nor technical feasible (Thomas Marx, personal communication, 16.03.2011).

A pre-commercial method of production is cathodic electro-deposition of CdTe thin-films. According to Fthenakis (2004) less than $1 \%$ of the $\mathrm{Cd}$ and Te are wasted during this process since deposition only occurs on surfaces held at the cathode. Zweibel (1999) states a material deposition rate of $95 \%$ in the electro-deposition pilot line. Additionally, he estimates that productions costs per square meter (capital costs plus maintenance and material costs) can be reduced by over $50 \%$ when using electro-deposition instead of vapour deposition. The US-company EncoreSolar was founded in 2010 to pursue this production technology (Basol BM, 2011; Encore Solar, 2012).

Due to the lack of information available and the various production processes in use, it is difficult to acquire reliable values for material utilisation rates There is also a high uncertainty as to how much of the overspray can be recovered and further purified. Thus, a relatively broad range of material utilization rates and recovery rates for the overspray are assumed for 2010. For the purposes of this research, the "breakthrough" scenario utilizes the best available technology, electro-disposition, by 2040. The other two scenarios employ the currently most widespread technologies, with gradually improving efficiency until 2040.

\subsection{Overall Equipment Efficiency}

Another waste stream is comprised of modules that fail during production, e.g. glass substrates that break during the high temperature production processes or modules, which do not fulfil quality or power specifications (flow "off-spec modules" in Figure 2). In thin-film production high overall equipment efficiencies are important to drive costs down. In scaled-up production an overall equipment efficiency of more than $90 \%$ is not uncommon; up to $98 \%$ is aimed for in a $1 \mathrm{GW}$ plant (Christian Kaufmann, personal communication, 19.03.2009, Arun Ramakrishnan, personal communication, 11.10.2010, Tom Clarius, personal communication, 02.05.2011). In pilot lines equipment efficiencies are considerably lower.

The "breakthrough" scenario uses an overall equipment efficiency rate of $95 \%$ for scaled-up production in 2010. In pilot lines an efficiency of $85 \%$ ("slow progress" scenario) is not unusual. In all scenarios, efficiencies are predicted to improve continuously until 2040. Due to the many process steps (up to 20) a cap of $98 \%$ is set in the "breakthrough" scenario; meaning that in average per process step, 1 out of 1000 modules is "off-spec". In the best case scenario, $100 \%$ of off-spec modules are recycled. In the other scenarios not all off-spec modules can be recycled in 2010, because not every producer has its own recycling plants and the recycling capacities of the existing pilot lines are still limited; this should, however, improve with time. 


\subsection{Lifetime probability}

The last waste stream included in the analysis is comprised of end-of-life modules. The amount of end-of-life modules depends on their lifetime. The lifetime is the time span between the module's production and the time a module is scrapped, either due to technical failures or for non-technical reasons. Therefore, the lifetime depends on many internal (e.g., power degradation, delamination) and external reasons (e.g., damage by hail or fire, profitability).

The lifetime is not to be mistaken with the power output warranty time, after which a module still reaches a certain performance (e.g. $80 \%$ of original power output after 25 years). Reliability studies suggest $0.8-1 \%$ relative power degradation per year (Enzenroth et al., 2007; Ross et al., 2007), indicating that the $80 \%$ power warranty threshold is reached after 20 to 25 years. Due to the robust construction of the modules designed to last at least the output warranty time, it is probable that modules can be used longer than this.

Due to the fact that the first CdTe-PV modules were installed in the 1990's, returns are still low. Therefore, reliable statistics on the lifetime of CdTe-PV modules don't exist. Consequently, a probability function is used to calculate the lifetime probability of CdTe-PV modules; for this the weibull distribution has been proven adequate (Elshkaki et al., 2005; Melo 1999):

$$
f(t)=\frac{\alpha}{\beta}\left(\frac{t}{\beta}\right)^{\alpha-1} e^{-\left(\frac{t}{\beta}\right)^{\alpha}}
$$

Formula 8

Melo (1999) describes how to calculate the shape parameter $\alpha$ and scale parameter $\beta$ by assuming a mode and presuming that a percentage of products will reach end-of-life within a certain time-span. This method is applied in this paper.

In this analysis, the lifetime probability of photovoltaic modules $p_{t, P V}$ in their year of age $t$ consists of two parts: probability of early returns of modules due to product defects or damages through transport and installation $p_{t, e r}$, and probability of modules first becoming deinstalled at end-of-life $p_{t, e o l}$. The percentage of "early returns" (ER) quantifies how much of the yearly production is returned in early life.

$$
p_{t, P V}=E R \cdot p_{t, e r}+(1-E R) \cdot p_{t, e o l} \quad \text { Formula } 9
$$

The yearly material outflow of Te "EoL-modules" of the stock "installed material" are calculated by formulas (2), (3), (8), and (9), taking into account all since 1999 installed CdTe-PV modules. Because it is unclear which weibull parameter represents the reality best, different modes are used (Table 2). In all scenarios $99.9 \%$ of the modules will be scrapped within 40 years ${ }^{4}$.

The percentage of overall production that is returned before the product warranty time (usually 5 years) depends on the module quality. Ross et al. (2007) report that warranty returns of First Solar's products have been reduced to less than $0.25 \%$. However the "Photovoltaik Magazin" reports that modules with a total capacity of about $30 \mathrm{MW}_{p}$, which were produced between June 2008 and June 2009 by First Solar, degraded significantly shortly after installation (photovoltaik-Magazin, 2012). Those warranty cases amount to $4 \%$ of First Solar's production of estimated $800 \mathrm{MW}_{\mathrm{p}}$ during this time span (First Solar, 2009, 2010). According to the information gathered from expert interviews, other thin-film manufacturers report return rates between $0.25 \%$ and $2 \%$. The "Study on the Development of a Take-Back-and Recovery System for Photovoltaic Products" approximates that $1.3 \%$ of sold PV modules are returned either because of damages during installation and transport or efficiency degradation during the first year of operation (Sander et al., 2007). In the "breakthrough" scenario an optimistic $0.25 \%$ of warranty returns are assumed. In the "steady advance" scenario it is assumed that $2 \%$ of the modules will come back, and in the "slow progress" scenario, respectively $4 \%$ of the modules would be returned (Table 2). The weibull parameters for early returns are chosen so that early returned modules will show up in the first 5 years of use.

\begin{tabular}{|l|l|l|l|l|}
\hline \multirow{2}{*}{} & \multirow{2}{*}{ ER } & \multicolumn{3}{|c|}{ Weibull parameters } \\
\cline { 3 - 5 } & & mode & $\alpha$ & $\beta$ \\
\hline Early returns & - & - & 0.9 & 1.0 \\
\hline Breakthrough & $0.25 \%$ & 32 & 12.8 & 32.2 \\
\hline Steady advance & $2.00 \%$ & 30 & 10.0 & 30.3 \\
\hline Slow progress & $4.00 \%$ & 28 & 8.2 & 28.5 \\
\hline
\end{tabular}

Table 2 Parameters of weibull distributions

\footnotetext{
${ }^{4}$ A sensitivity analysis showed that the amount of end-of-life waste arising in 2040 is strongly dependent on the assumed mode of the weibull-distribution, whereas the effect of varying the longest technical lifetime is marginal.
} 


\subsection{Recycling and refining}

Both production rejects (off-spec modules) and end-of-life modules can be treated to recover the raw materials. Several processes to recover CdTe from CdTe-PV modules were developed on the lab- and demonstration-scale (Berger et al., 2010; Bohland et al., 2002; Campo et al., 2003; DeFilippo, 2011; Fthenakis and Wang, 2006; Goozner et al., 1999; Kernbaum, 2011; Palitzsch, 2010). The German company saperatec is building a pilot scale process line for the separation of thin-films from glass substrates (Kernbaum, 2011). Loser Chemie, a producer of chemicals for water treatment, has developed a universal process to recover thin-film metals from PV modules and production residues (Palitzsch, 2010). The materials produced from both companies have to be further processed and purified by a refinery.

Currently, the only industrial scale CdTe-PV module recycling facilities are run by First Solar - and are mainly involved in the treatment of production scrap. First Solar claims to recover $95 \%$ to $97 \%$ of CdTe, which then ends up in a filter cake (Krueger, 2010; Lisa Krueger, personal communication, 07.09.2009). Out of this filter cake and other residues from production, the refinery $5 \mathrm{~N}$ Plus extracts $80 \%$ to $95 \% \mathrm{Cd}$ and Te that can be reused in $5 \mathrm{~N}$ (99.999 \%) CdTe synthesis (Andreas Wade, personal communication, 25.11.2010; Lisa Krueger, personal communication, 07.09.2009; Suys, 2010). Besides CdTe/CdS residues 5N Plus also recycles nonlaminated substrates and laminated modules.

In the "breakthrough" scenario, all off-spec modules are treated; $97 \%$ of the Te can be recovered during module recycling, and $90 \%$ turned into $5 \mathrm{~N}$ Te in a refinery. In the "slow progress scenario" it is assumed that $20 \%$ of off-spec modules are discarded (e.g. deposited in landfills) as not every factory has its own attached recycling plant. Also, less thin-film material, just $90 \%$, is recovered during recycling and $80 \%$ of this recycled material can be synthesised into $5 \mathrm{~N}$ CdTe. The transfer coefficients of the "steady advance" scenario lie approximately in the middle of the other two scenarios. In all scenarios the coefficients improve over time.

\subsection{Collection}

What percentage of the modules will be collected in the future is unclear. In Europe, photovoltaic producers have founded the initiative "PV Cycle". The aim of this organisation was at creating a voluntary, industry-wide take-back and recycling program for end-of-life modules in Europe, but the environmental agreement proposed to the European Commission by PV Cycle was rejected. Thus, although currently excluded from the European e-waste directive, PV modules will, in the future, be subject to the revised e-waste directive. The legislation foresees the possibility to join a collection scheme such as PV Cycle or to fulfil the obligation by collecting and recycling modules individually. The legislation imposes collection rates for PV modules of up to $85 \%$ and recycling rates up to $80 \%$ (European Parliament, 2012). As glass already makes up more than $95 \%$ of CdTe-PV module's weight (Sander et al., 2007), this legislation doesn't guarantee the recovery of the thin-film materials.

Currently, the collection rates of household e-waste in industrialized states are still quite low. In Europe, rates are reported at roughly $25 \%$ (medium sized appliances) to $40 \%$ (larger appliances) (Huisman et al., 2008); In the USA, $8 \%$ of mobile devices and $38 \%$ of computers are recycled (EPA, 2011). An assessment of various compliance schemes in Europe concludes that it should be possible to collect around $75 \%$ of the large appliances (Huisman et al., 2008).

In addition to statutory provisions also softer instruments exist, which guarantee the take back and recycling of modules. For example, a loan from the German development bank "Kreditanstalt für Wiederaufbau (KfW)" requires the system-installer or module-producer to take back and dispose the modules at no charge in accordance with regulation (KfW, 2009). Another possibility is individual collection schemes. First Solar has set up an individual collection and recycling program that includes, among other measures; managing collection, setting aside funds, and requiring the owner to register their installation (First Solar, 2011b). Presumably, other CdTe-PV producers will follow a similar approach of individual producer responsibility.

In the scenarios presented, the collection rates for end-of-life PV modules can be considered quite high for two reasons; as CdTe-PV modules contain hazardous $\mathrm{Cd}$, producers are required by the general public and the lawmaker to have efficient collection schemes. Furthermore, the installation of PV modules - usually within a large PV system - is less dissipative than the use of small electric appliances. In all scenarios collection rates improve over time.

Table 3 shows the underlying data of the material flow analysis that was presented above. Each combination represents one scenario. Values between 2010 and 2040 are interpolated. 


\begin{tabular}{|l|l|l|l|l|l|l|}
\hline Scenario & \multicolumn{2}{|c|}{ Breakthrough } & \multicolumn{2}{c|}{ Steady advance } & \multicolumn{2}{c|}{ Slow progress } \\
\hline Year & 2010 & 2040 & 2010 & 2040 & 2010 & 2040 \\
\hline Annual installation $\left[\mathrm{GW}_{\mathrm{p}}\right]$ & 1.5 & 12.2 & 1.5 & 8.1 & 1.5 & 4.0 \\
\hline Conversion efficiency $\mathrm{n}[\%]$ & 11.3 & 18.0 & 11.3 & 16.5 & 11.3 & 15.0 \\
\hline CdTe-layer thickness $[\mu \mathrm{m}]$ & 2 & 0.1 & 2.5 & 1 & 3 & 2 \\
\hline Material utilization rate & $75 \%$ & $99 \%$ & $65 \%$ & $85 \%$ & $55 \%$ & $70 \%$ \\
\hline Overspray recovery & $75 \%$ & $99 \%$ & $50 \%$ & $75 \%$ & $70 \%$ & $85 \%$ \\
\hline Overall equipment efficiency & $95 \%$ & $98 \%$ & $90 \%$ & $95 \%$ & $85 \%$ & $90 \%$ \\
\hline Collection off-spec modules & $100 \%$ & $100 \%$ & $90 \%$ & $100 \%$ & $80 \%$ & $90 \%$ \\
\hline Collection EoL modules & $95 \%$ & $99 \%$ & $80 \%$ & $90 \%$ & $65 \%$ & $80 \%$ \\
\hline Material recovery module recycling & $97 \%$ & $99 \%$ & $95 \%$ & $97 \%$ & $90 \%$ & $95 \%$ \\
\hline Material recovery refining & $90 \%$ & $95 \%$ & $85 \%$ & $90 \%$ & $80 \%$ & $85 \%$ \\
\hline
\end{tabular}

Table 3 CdTe-PV production, conversion efficiencies, layer thickness, and transfer coefficients of three different scenarios.

\subsection{Storylines}

In the following paragraphs, storylines are used to describe plausible future developments in each scenario, based on the set of assumptions in Table 3. They reflect, illustrate, and validate the quantitative assumption by setting them into the broader context, considering qualitative, technological, economic, and legislative issues.

\section{Scenario "breakthrough"}

High market growth rates and fast technological development are mutually beneficial. CdTe-modules stand out because of their high efficiencies, good performance, and high product quality. More than $94 \%$ of the modules produce energy for more than 25 years. Due to efficient take-back and collection systems just a few end-of-life modules will find their way around the compulsory recycling laws. Strict environmental regulations have been passed stipulating high collection rates and material specific recycling quotas for critical materials. This development goes together with high enough commodity prices to cover declining recycling costs due to economy of scale. High commodity prices also lead to major efforts to reduce material use in manufacturing and to reduce the thickness of the CdTe-layer, which can be achieved thanks to efficient light trapping.

\section{Scenario "steady advance"}

The CdTe-PV output increases with reasonable growth rates. The product quality and performance is satisfying; only $16 \%$ of the modules return within 25 years. Due to material efficiency measures and improved yields the production costs decrease further. There is no ban on using Cd in PV in Europe or USA, but environmental laws are strict. Producers have to make sure that collection and recycling is improved as current collection is dissatisfying. Due to a lack of onsite recycling capabilities by CdTe-PV producers, not all production discards are recycled.

\section{Scenario "slow progress"}

The industry experiences product quality problems that lead to a high amount of warranty returns in the first years of use. Due to a fast degradation of power output, over $30 \%$ of all modules are already returned before they reach the output warranty time of 25 years. Industry and research are experiencing problems in increasing cell efficiency and in reducing layer thickness below $2 \mu \mathrm{m}$. Due to the slow technological development, the price advantage of CdTe-PV compared to other PV technologies can't be sustained. Therefore CdTe-PV looses market shares. Due to inefficient collection systems and take-back programs, the collection rate is lower than in the other two scenarios. Moreover, the time it takes to scale-up pilot recycling processes and run them efficiently will have been underestimated.

\section{Results}

In the following paragraphs the results of the material flow analysis are presented. Figure 4 shows the amount of Te bound in produced modules (left axis) as a function of the yearly produced capacity of CdTe-PV (right axis) for the three different market scenarios. Although the "steady advance" scenario starts off with less material bound in produced modules, it soon overtakes the slow progress scenario. In all scenarios the amount of Te installed annually drops after a peak in between 2018 and 2022 due to measures taken at module level to improve material efficiency; higher module efficiencies and thinner material layers compensate the market growth. Therefore the amount of Te installed in the "steady advance" scenario nearly equals that of the "slow progress" scenario in 2040, although double the capacity is being installed. 


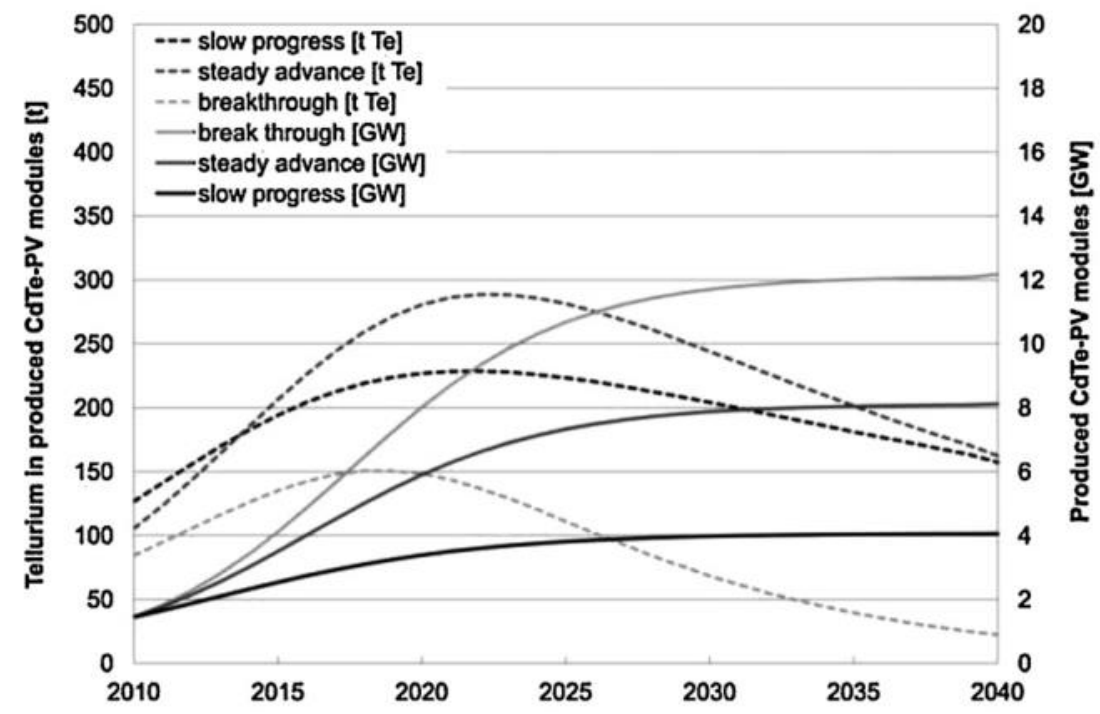

Figure 4 Three scenarios of yearly produced capacity (right axis) and tellurium bound in produced modules (left axes).

The peak can also be seen in Figure 5, which depicts the feedstock for production, i.e. the "primary" demand plus the recycled material from production scrap and end-of-life modules. In the "breakthrough" scenario, material efficiency measures can best compensate the market growth; the highest market growth goes hand in hand with the lowest Te feedstock of all scenarios. For the "slow progress" scenario the compensation doesn't work as good as for the other two scenarios; the feedstock is all the time the highest.

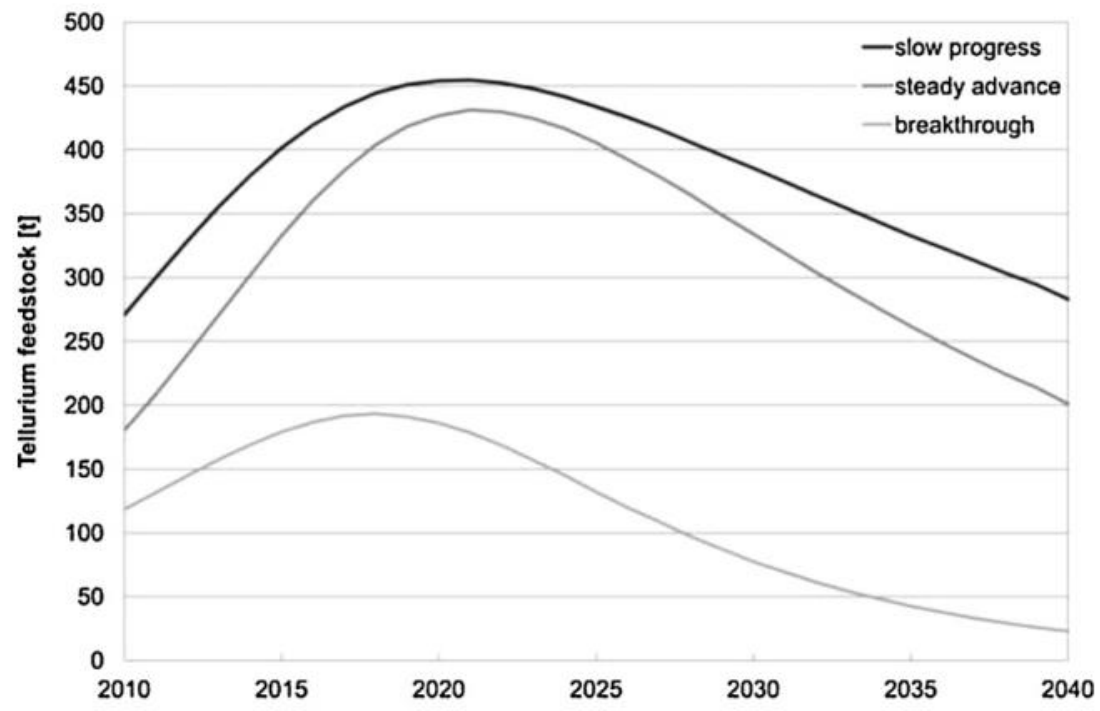

Figure 5 Feedstock of different scenarios

The indicator metric tonnes Te feedstock needed per giga watt peak produced modules (Figure 6) shows both the effect of material efficiency measures in production (material utilization, overall equipment efficiencies) and the material efficiency measures on module level (layer thickness, conversion efficiency). In 2010, between $82 \mathrm{t}$ and $187 \mathrm{t}$ of Te feedstock is needed to produce one giga watt of CdTe-PV modules. This means that in the "slow progress" scenario $152 \mathrm{t}$ more Te is needed than in the "breakthrough" scenario (118t) to produce the same capacity (1.5 GW in 2010). The specific feedstock demand is potentially improved in 2040 by $98 \%$ in the "breakthrough" scenario, $80 \%$ in the "steady advance" scenario, and $63 \%$ in the "slow progress" scenario. 


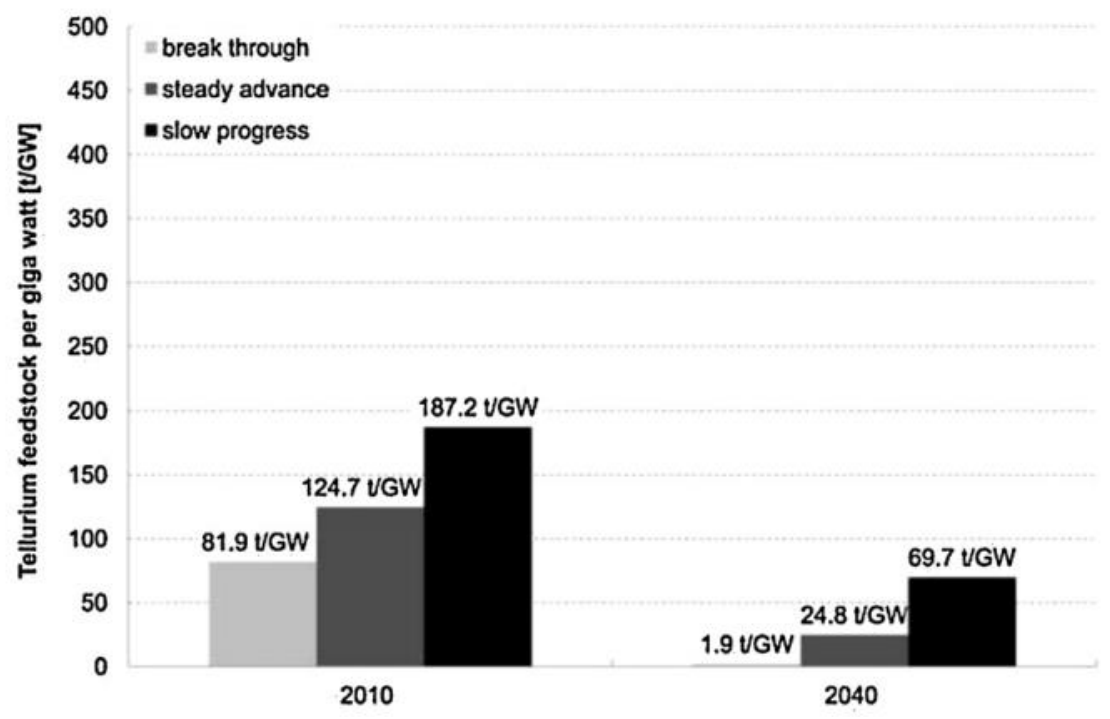

Figure 6 Feedstock per giga watt

Figure 7 shows the feedstock of the "slow progress" scenario composed of external supply (flow "demand"), recycled Te from CdTe-PV production scrap, and recycled Te from end-of-life modules. A peak value of $455 \mathrm{t} \mathrm{Te}$ will be needed in 2021 to produce $3.5 \mathrm{GW}_{\mathrm{p}}$ of CdTe-PV modules, or $130 \mathrm{t} / \mathrm{GW}_{\mathrm{p}}$ (30\% improvement since 2010). The amount of recycled material from production scrap is predicted to decline from 2020 onwards due to efficiency measures, while the amount of Te resulting from end-of-life (EoL) recycling becomes more significant (see also Figure 12).

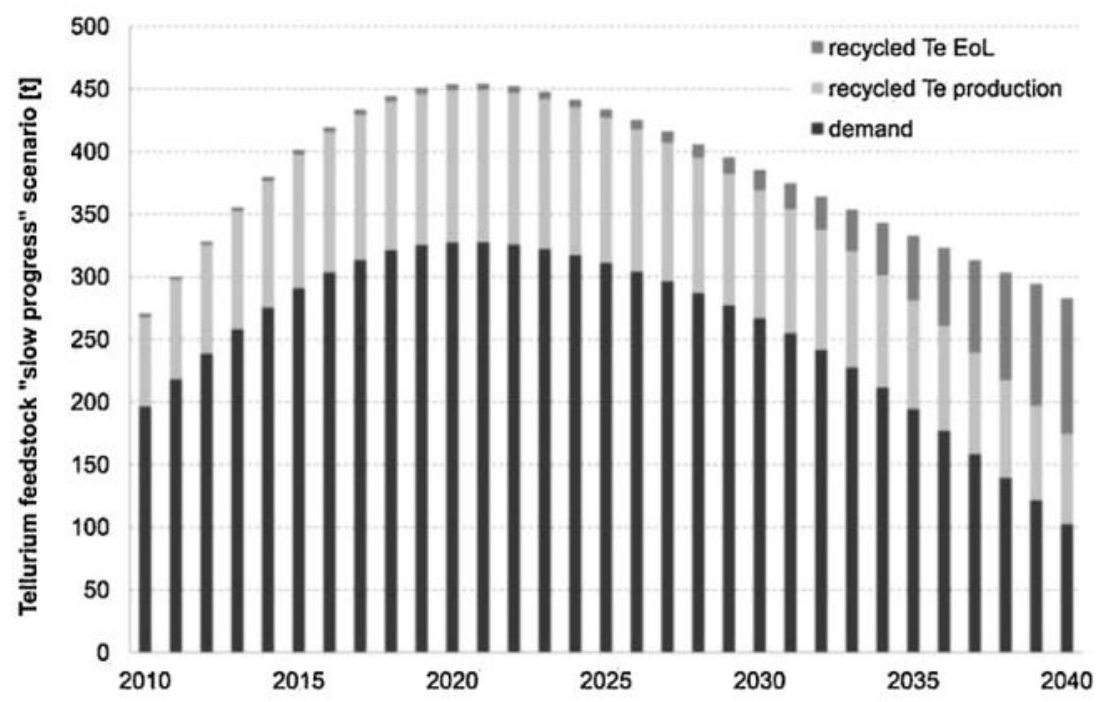

Figure 7 Tellurium feedstock in the "slow progress" scenario

In the "breakthrough" scenario, due to the high material utilization, production waste is predicted to play an inferior role compared to the recycled Te from EoL modules from 2034 onwards. The latter will actually surpass the feedstock by $60 \%$ in 2040 (Figure 8). In this scenario, the CdTe-PV industry could be self-contained by 2038. 


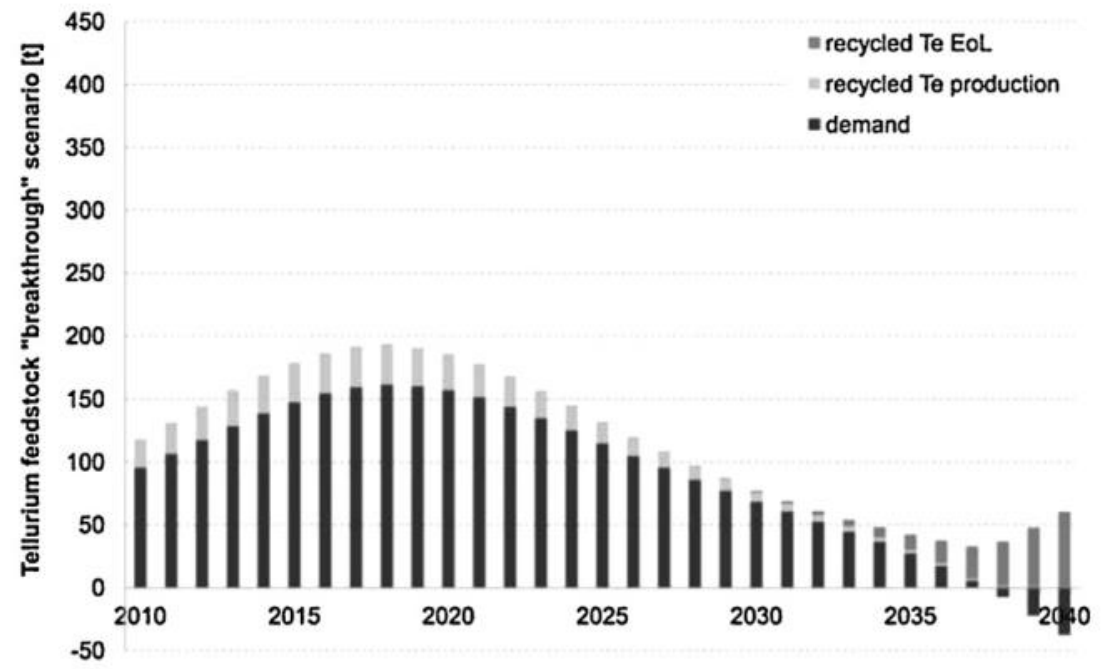

Figure 8 Tellurium feedstock in the "breakthrough" scenario

Even more interesting than the feedstock is the Te demand (Figure 9), because it indicates how much material has to come from external sources. Examples of possible sources are: primary Te from mining or recycled Te from other industries. The difference between the feedstock and demand at peak times amount to around $30 \mathrm{t}$ in the "breakthrough" scenario, $90 \mathrm{t}$ in the "steady advance" and $200 \mathrm{t}$ in the "slow progress" scenario. In the "breakthrough" scenario the CdTe-PV industry could recycle more material from end-of-life modules than is necessary for production by 2038 (Figure 8).

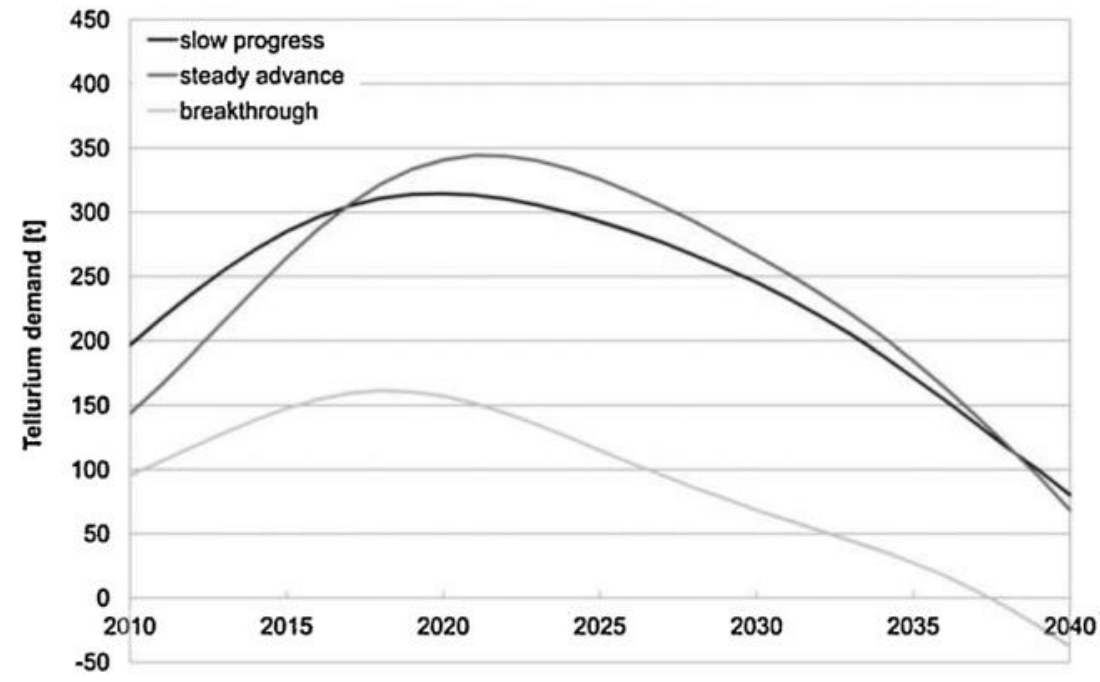

Figure 9 Tellurium demand

To assess the efficiency of the production system, the three indicators: "material utilization", "recovery rate", and "scrap rate" have been compared for each scenario below (Figure 10; definition of indicators in section 2). In 2010 about $50 \%$ to $70 \%$ of the feedstock is used in the final product and between $50 \%$ and $70 \%$ of Te found in production scrap (overspray and off-spec modules) is able to be recovered. Thus, $10 \%$ to $30 \%$ of the feedstock is scrapped. It is notable that in 2010 the recovery rate in the "slow progress" scenario is higher than in the "steady advance" scenario, primarily because more of the overspray can be recycled in the former scenario. But, because the material utilization is much lower in the "slow progress" scenario, the absolute amount of scrap is higher than in the "steady advance" scenario. In 2040 this situation reverses and the recovery rate of the "steady advance" scenario is $4 \%$ higher than in the "slow progress" scenario; however, the recovery rate is still $20 \%$ below that of the "breakthrough" scenario. Material utilization is predicted to increase by $16 \%$ to $26 \%$ by 2040 . In the "breakthrough" scenario nearly $100 \%$ of feedstock is bound in the cells or recycled in 2040, whereas in the "slow progress" scenario $12 \%$ of the feedstock is still scrapped. 


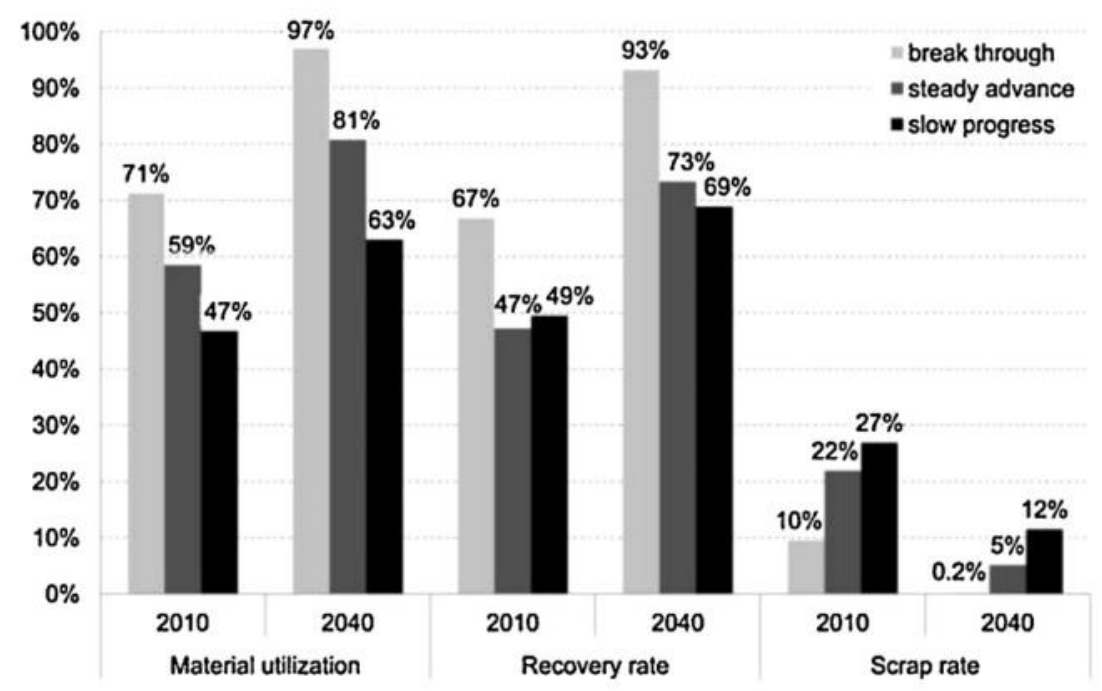

Figure 10 Material utilization, recovery rate, and scrap rate in production

The composition of production scrap of the "slow progress" scenario, the scenario with the highest amount of production scrap, is illustrated in Figure 11. In the "slow progress" and "steady advance" scenarios, the share of overspray at production scrap is above $78 \%$ during the whole time-span. In the "breakthrough" scenario, the share falls to one third of overall production scrap in 2040 due to the high material utilization in the deposition process.

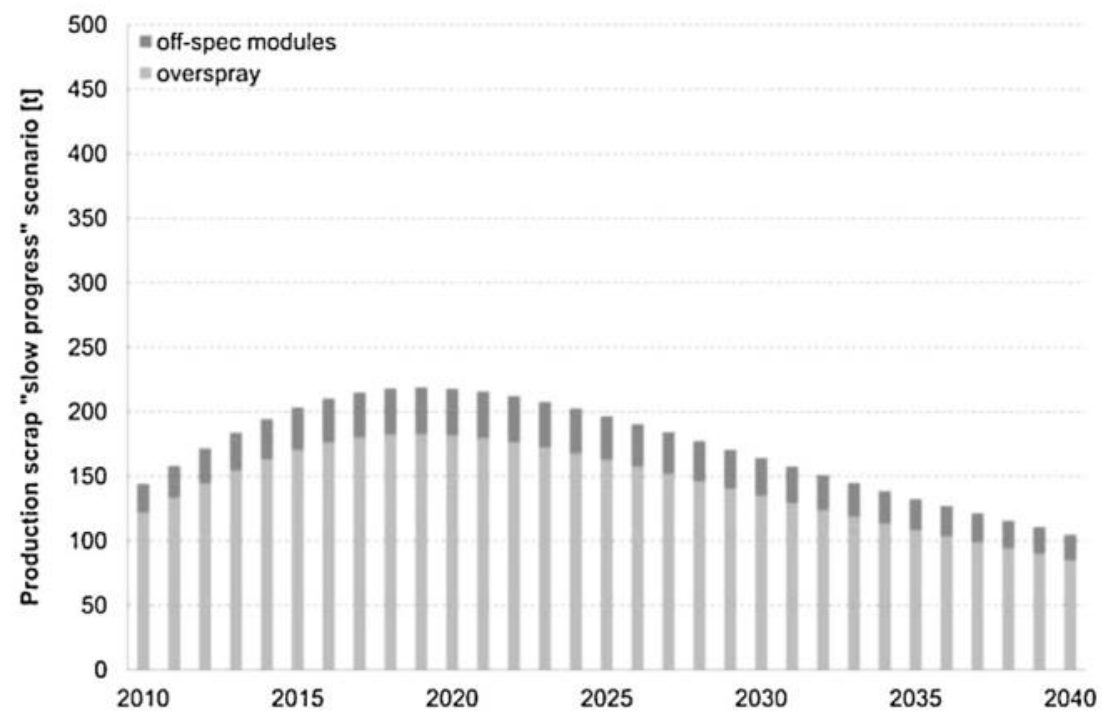

Figure 11 Composition of production scrap ("slow progress" scenario)

In the "breakthrough scenario the amount of Te bound in end-of-life modules (Figure 12) will surpass the amount of production scrap in 2033. In the "steady advance" scenario this will happen in 2036, and in the in the "slow progress" scenario in 2038. It should be noted that in the "slow progress" scenario the amount of end-of-life Te is at its highest, although more Te is found in installed modules in the "steady advance" scenario (Figure 4 and Figure 15). This is because modules will be scrapped earlier in the "slow progress" scenario than those in the other two scenarios. Depending on the scenario, the mode (the peak of the lifetime probability function, i.e. the most realistic lifetime) moves in time, such that in the other two scenarios fewer modules will be scrapped before 2040. Thereafter, it will change as indicated by the gradient of the dotted curves. In 2040, the amount of Te recycled from EoL modules in the "steady advance" scenario will actually be nearly as high as in the "slow progress" scenario. The amount of end-of-life Te, which is recycled and fed back into production, equals the amount of Te in EoL modules multiplied by the annual "end-of-life recycling rate" seen in Figure 13 for the years 2010 and 2040. 


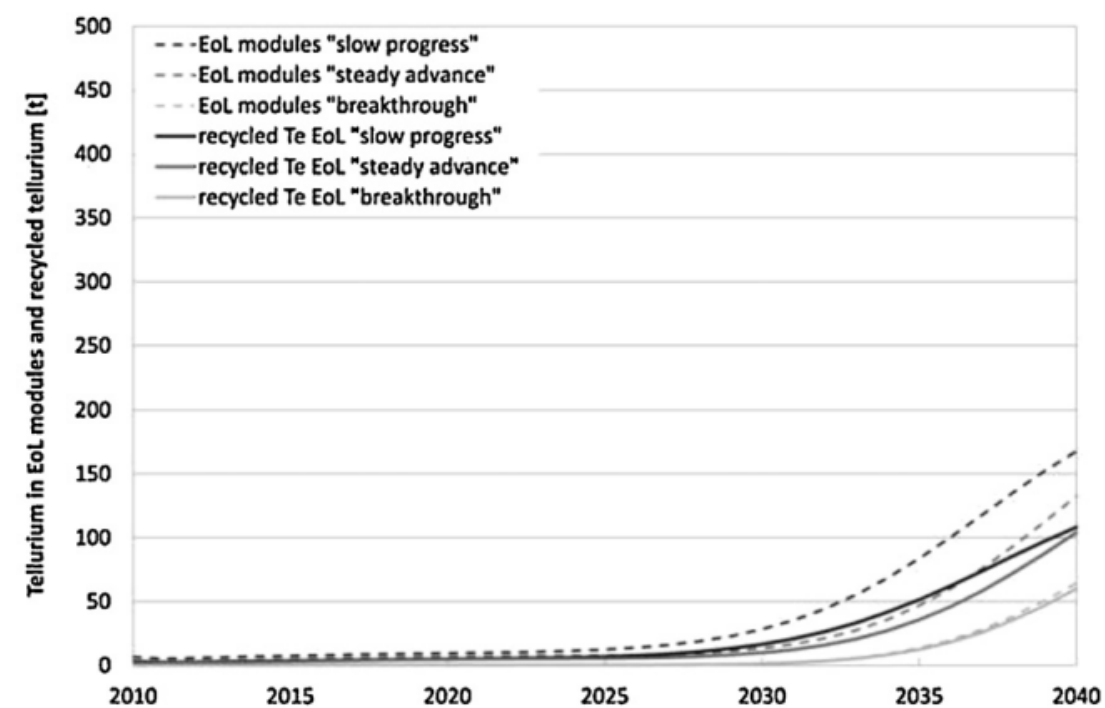

Figure 12 Tellurium bound in end-of-life modules and recycled tellurium from end-of-life modules

Of course the "breakthrough" scenario has the highest recycling rate, but even in $2040,7 \%$ of the Te is lost along the chain "collection", "module recycling", and "refinement".

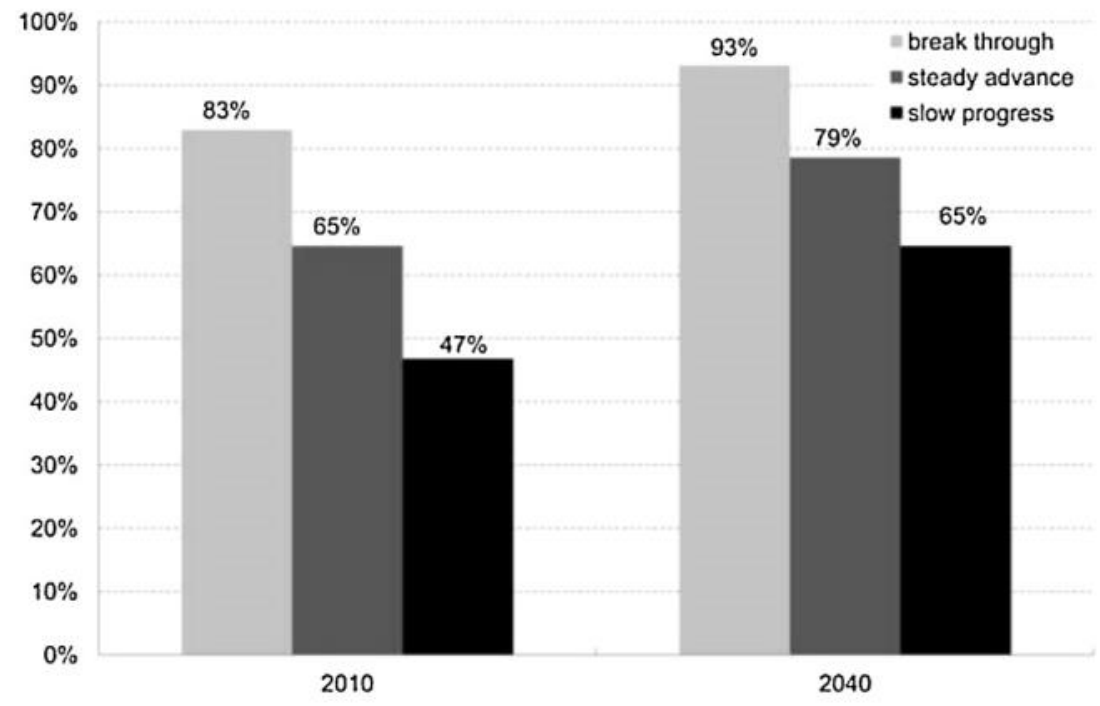

Figure 13 End-of-life recycling rate

The total cumulative amount of Te waste disposed of (stock "discarded material" in Figure 3) can be seen in Figure 14. The amount of Te disposed as production scrap and end-of-life waste is the highest in the "slow progress" scenario. In this scenario 2,620 t Te will leave the life cycle within 30 years. In the "breakthrough" scenario just $7 \%$ of that amount is predicted to accumulate in waste deposits or dissipate in the environment. 


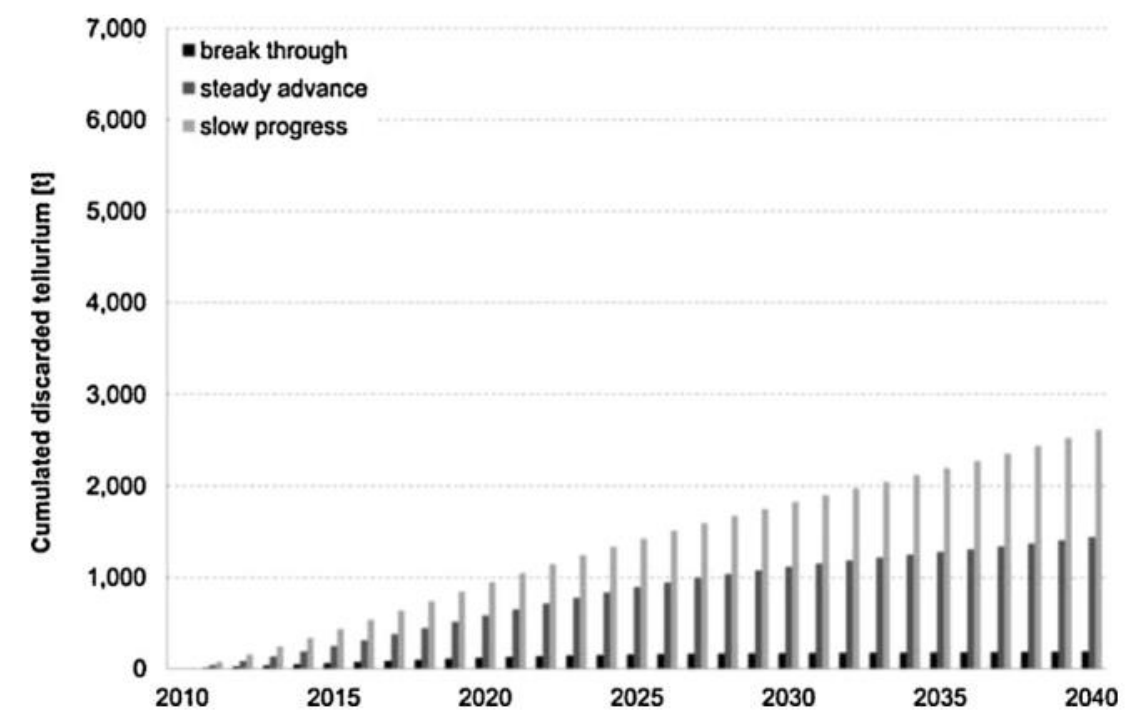

Figure 14 Stock of discarded tellurium

The amount of Te that is not exiting the material cycle accumulates in installed modules as a new stock (Figure 15). In 2040, this "urban mine" is predicted to contain from 2,780 t ("breakthrough") to 6,300 t Te ("steady advance") in modules installed since 1999. This stock will not start to "shrink" until the late 2030's. I.e. more Te will then leave the stock in end-of-life modules than Te is added in newly installed modules.

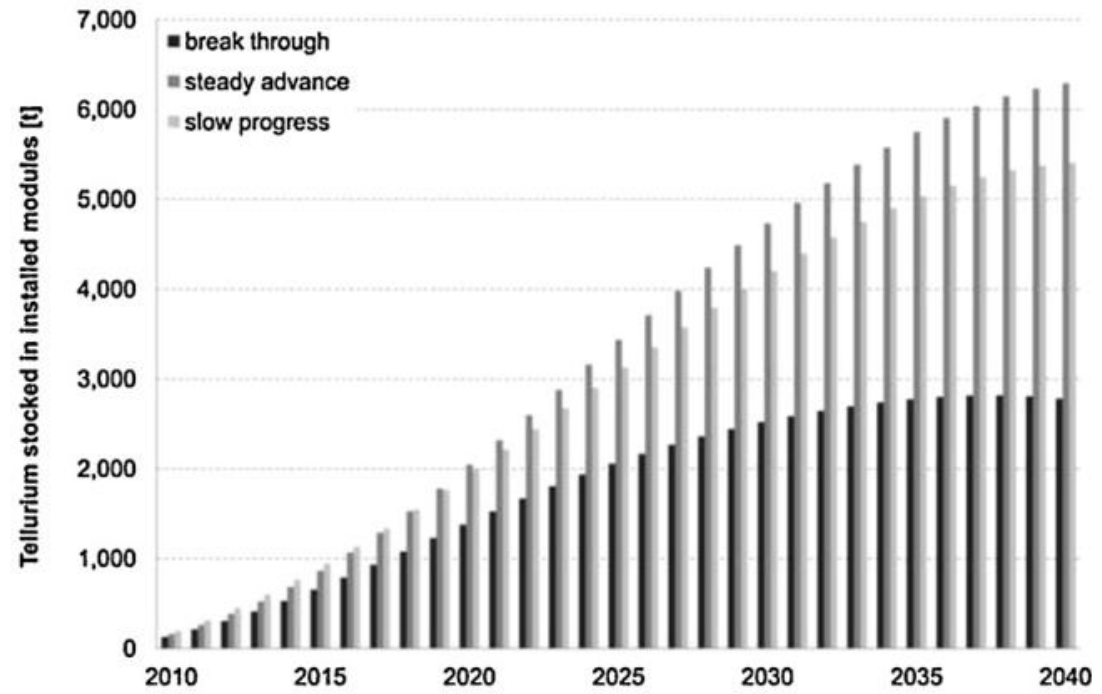

Figure 15 Tellurium stocked in installed modules

\section{Discussion}

According to the scenarios described, the Te demand for CdTe-PV in 2010 is estimated to equal from one to two fifths of worldwide Te production (Appendix). After this the demand continues to grow until it reaches its peak between 2018 and 2021. The highest demand is reached in 2021, with a maximum of $344 \mathrm{t}$, as seen in the "steady advance" scenario. The total amount of Te produced in $2020(1,400 \mathrm{t})$ and $2030(1,850 \mathrm{t})$ as predicted by Fthenakis (2009) and Zweibel (2010) suggest that no temporary shortage in supply will occur, as long as the increase in demand for other applications stays below $12 \%$ to $16 \%$ per year. To check this conclusion we doubled the market share of CdTe-PV in the "steady advance" scenario to $10 \%$ in 2040 (ceteris paribus). In this case, the demand peaks at $610 \mathrm{t}$ in 2024 . Hence even in this modified scenario a Te shortage seems implausible. However, Te production will have to adapt to the increased demand from CdTe-PV until peak times. After demand peaks, efficiency measures in production and an increase in Te from recycled end-of-life modules lead to a decline of demand despite market growth.

Figure 16 shows the Te feedstock per giga watt compared to the estimations from Zuser and Rechberger (2011), Andersson (2000), Fthenakis (2009), and Zweibel (2010). The error bars indicate the maximal and minimal of specific feedstock according to the scenario assumptions of the authors. A similar trend in decreasing Te feedstock from 2008 to 2040 is noticeable, with the highest changes between 2010 and 2020. 
Note that Andersson (2000) and Zweibel (2010) calculate the feedstock on the basis of the material content in the cell, and by doing so underestimate the real demand for production ${ }^{5}$.

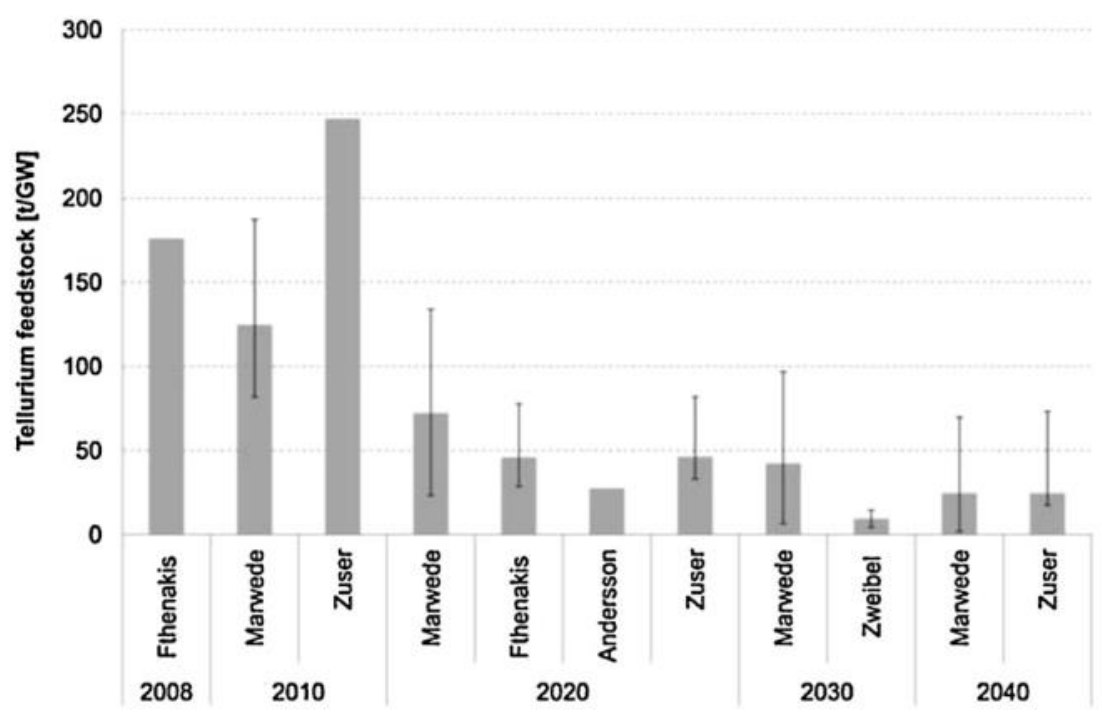

Figure 16 Tellurium demand per giga watt produced

Zuser and Rechberger (2011) and Fthenakis (2009) also look at the relevance of recycling of end-of life modules. Zuser and Rechberger (2011) assume that modules are replaced after 20 years of operation and that $90 \%$ of the Te will be recovered. Fthenakis (2009) assumes a module lifetime of 30 years and an average $10 \%$ loss in each module collection and recycling. In Fthenakis' estimations of Te availability for CdTe-PV, about $10 \%-20 \%$ comes from recycled Te in 2040. In Zuser's and Rechberger's analysis, the share of recycled Te from EoL modules at Te demand accounts for $20 \%$ in 2040. In this MFA, recycled Te from EoL modules make up around $50 \%$ of the feedstock in the "steady advance" scenario, and $40 \%$ in the "slow progress" scenario respectively. In the "breakthrough" scenario the amount of recycled Te from end-of-life modules actually surpasses the feedstock needed in 2040 by $40 \mathrm{t}$. This is because the efficiency measures on process and module level has driven down the feedstock needed per $\mathrm{GW}_{\mathrm{p}}$ produced modules by $98 \%$. One can conclude that although assumptions on market development, material demand, lifetime, and recycling rates differ in all studies, $10 \%$ to $50 \%$ of the Te needed for CdTe-PV production could realistically come from EoL modules by 2040 .

While the share of recycled Te from end-of-life modules at the feedstock increases over time, the absolute amount of overall production scrap declines due to efficiency measures. Overspray makes up the biggest share of production scrap. In the "slow progress" scenario the most production scrap of all scenarios is generated due to the material inefficiency in production.

In the "breakthrough" scenario the biggest market success is accompanied by the lowest cumulated demand and the least discarded material. In all scenarios, the recycling rates in the production and end-of-life phase are increasing, but still $7 \%$ ("breakthrough") to 33 \% ("slow progress") of the cumulated demand is "lost". The amount of Te that is not leaving the material cycle is piling up as an "urban mine". The most Te accumulates in the "steady advance" scenario, although the cumulated installed power ( $\left.181 \mathrm{GW}_{\mathrm{p}}\right)$ is just two thirds of the "breakthrough" scenario. Nevertheless, the most Te arises in end-of-life modules in the "slow progress" scenario because modules are scrapped at an earlier time. However, the amount of recycled Te in the "steady advance" scenario reaches that of the "slow progress" scenario in 2040 due to the higher efficiency of the recycling chain and a faster growing end-of-life stream. In general, the depletion of this "mine" is delayed until the late 2030s due to the long lifetime of the modules.

\footnotetext{
${ }^{5}$ In Fthenakis' (2009) analysis, the Te feedstock in 2008 is 1.75 times the module's content calculated on the basis of his assumptions on layer thickness and conversion efficiency (1.2 times the material content in 2020). Zuser and Rechberger (2011) calculate the specific feedstock based on conversion efficiencies, layer thickness, and material utilization rates.
} 


\section{Conclusion}

The material flow analysis shows that recycled Te from photovoltaic production scrap and end-of-life modules can make up a significant share of the feedstock. In the best case, these recycling flows together with material efficiency measures on module and process level can reduce the "primary" Te demand to below zero by 2038. Because material efficiency measures cannot compensate for market growth until approximately 2020, a temporary shortage may occur if Te production capacities are not scaled up fast enough. This could temporarily lead to high prices until Te production has expanded. When demand from CdTe-PV declines, overcapacities in Te production may have to be cut back.

The MFA and the interviews indicate that not all overspray can be recovered due to the dissipation in the equipment and to the contamination with $\mathrm{Cd}$ and equipment materials. Because of this, a high material utilization during deposition is crucial. Some of the recovered materials such as the scrapings from the shields and deposition chamber have to be disposed of as hazardous waste. Further research is also needed for examining the entire recycling chain and the total amount of waste disposed.

Off-spec modules contribute only marginally to production waste, but they can be used in combination with early returns as feedstock for the start-up recycling companies until more end-of-life modules are available. Currently, the recycling costs exceed the material value of the PV modules (including glass substrates and other materials). Producers have to set aside funds to guarantee that recycling and logistics costs can be covered. Despite high recycling costs, the use of toxic $\mathrm{Cd}$ should require module recycling with the additional benefit of recovering Te. In addition to other factors, such as material prices, logistics, and energy prices, two diametrically opposed aspects will influence the economics and feasibility of recovering Te in the future: Firstly, economy of scale economy caused by growing waste streams and secondly, the declining material content of the modules. It is still unclear whether recycling can become economically sustainable in the future. Until economical profitability is clear, regulatory measures, economic incentives, and producer responsibility should be used to assure the take-back and recycling of CdTe-modules to avoid Cd emissions and secure valuable Te. If producers would still own CdTe-PV modules in use (as in leasing business models), they could secure the access to the valuable resources accruing in installed modules. However, the long lifetime of the modules delays the stock's depletion for nearly 30 years. Efficient collection and take-back programmes are vital in ensuring that modules will be handled appropriately. Still, reliable data about the lifespan of modules is needed. Many other aspects in addition to technical failures have to be taken into account when modelling module waste streams. It might for example become profitable to demount PV power plants after payback time (usually less than 20 years) to make use of conversion efficiency gains of new modules (repowering). Demounted modules can then be recycled for material recovery, but they may also be refurbished for re-use prolonging their lifetime. Statistics on returns are necessary to model lifetime probability more accurately.

There are also relevant uncertainties related to the market and technological development. New material extensive technologies like concentrator cells or dye-sensitized cells for example, could act as substitutes for CdTe-PV. The scenarios in this paper try to reflect these uncertainties, but so called "wild cards", i.e. events with low occurrence of probability but significant effects, are not considered in the assumed linear developments. For example, a legal ban of Cd use for PV, which was already controversially discussed before the last recast of the European RoHS directive (pv magazine, 2010), could mean at least for some regions the end of this PV technology. The scenarios illustrated here describe what would happen when the system develops as predicted. The purpose of the scenarios is to open up room for decisions to change the system to self-set targets. These targets include high material utilization during deposition, recycling of production scrap and end-of-life modules to preserve Te resources, close observation and avoidance of cadmium emissions further down the recycling chain, as well as precise cadastral and efficient collection systems. These measures are the key for a sustainable deployment of CdTe-PV.

\section{Appendix}

Due to the lack of published facts available from metal refineries, details about current tellurium (Te) production volumes are highly unknown. In general, the concentration on Te minerals is insufficient to allow an economic recovery as principal mining product; therefore, it depends on the concentration on the processing of other non-ferrous metals like copper, zinc, gold, and lead. Copper ores are the primary source of commercial Te. Te reserves contained in copper resources are estimated to 22,000 $t$ (USGS, 2011b). Te found in anode slimes from copper electro-refining were an estimated 1,300 t in 2005 (Green, 2006b) and 1,200 t in 2006 (Ojebuoboh, 2008); $30 \%$ to $45 \%$ of the Te content in the slime is recovered as metal product (ECN, 2010; Ojebuoboh, 2008). Hence, in 2005/2006 360 to 585 t Te were produced. For 2010, the United States Geological survey estimates the annual Te production to be between 450 and $500 \mathrm{t}$ (USGS, 2011a). Annual Te demand from all markets are estimated to be $475 \mathrm{t}$ in 2006 (Ojebuoboh, 2008) and $410 \mathrm{t}$ in 2008 (Fthenakis, 2009). Te is used for metallurgy ( $50 \%)$, in the chemical industry ( $20 \%)$, and for electronic devices like PV, infrared and 
thermoelectric devices ( $25 \%$ ). The highest demand growth is foreseen for electronic devices and CdTe-PV (ECN, 2010; Green, 2006a; Ojebuoboh, 2008). The anticipation of the growing Te demand will probably lead to more Te production due to annual demand growth rates for copper and higher recovery rates of Te in slimes. Scenarios predict an annual Te production of 1,400 t in 2020 (Fthenakis, 2009) and 1,850 t in 2030 (Zweibel, 2010) from copper electro-refining. Besides there are Te-rich mineral deposits in China and Mexico known, from which direct mining of Te is economically sustainable, containing in total about 2,500 t of Te (J. Guilinger as reported in Andersson, 2000; USGS, 2011a). In 2010 the Chinese company Apollo Solar Energy, Inc started mining Te from two mines, the Dashuigou and the Majiagou project containing $765 \mathrm{t}$ of Te (USGS, 2011a). From those mines the company expects to obtain approximately $50 \%$ to $60 \%$ of the Te needed for their products by the end of 2011 (Apollo Solar Energy, Inc, 2011). A five year purchase contract between Apollo Solar and unknown CdTe-PV manufacturer has been signed to provide $5 \mathrm{~N}$ Te with projected sales of about 110 Mio US-\$ (Apollo Solar Energy, Inc, 2010).

\section{Acknowledgements}

I thank my interview partners: Tom Clarius, Avancis; Christian Kaufmann, Helmholtz Zentrum Berlin; Lisa Krueger, First Solar; Thomas Marx, CS Service GmbH; Arun Ramakrishnan, Centrotherm; Andreas Wade, First Solar; the anonymous reviewers and Oliver Cencic, TU-Wien for his support with STAN. 


\section{References}

Amin N, Sopian K, Konagai M. Numerical modeling of CdS/CdTe and CdS/CdTe/ZnTe solar cells as a function of CdTe thickness. Solar Energy Materials and Solar Cells 2007;91(13):1202-8.

Andersson BA. Materials availability for large-scale thin-film photovoltaics. Progess in Photovoltaics: Research and Applications 2000(8):61-76.

Apollo Solar Energy, Inc. Apollo Solar Energy announces a long-term purchase contract from a major solar company. Chengdu, China; 2010.

Apollo Solar Energy, Inc. Quarterly Financial Report: For the quarterly period ended June 30, 2011; 2011.

Ayres RU. Industrial Metabolism. In: Ausubel, Sladovich, editors. Technology and Environment. Washington DC: National Academy Press; 1989.

Basol BM, inventor; EncoreSolar, Inc, assignee. Method of fabricating solar cells with electrodeposition compound interface layers. United States Patent. US 2011/0259424 A112011.

Berger W, Simon F, Weimann K, Alsema EA. A novel approach for the recycling of thin film photovoltaic modules. Resources, Conservation and Recycling 2010;54(10):711-8.

Bohland JR, Anisimov II, Dapkus TJ, Sasala RA, Smigielski KA, Kamm KD, inventor; First Solar, LLC, assignee. Reclaiming metallic material from an article comprising a non-metallic friable substrate. United States Patent. 6391165 B12002.

Bouman M, Heijungs R, van der Voet E, van den Bergh JCJM, Huppes G. Material flows and economic models: an analytical comparison of SFA, LCA and partial equilibrium models. Ecological Economics 2000;2000(32):195-216.

Brunner PH, Ma H. Substance Flow Analysis. An indispensible tool for goal-oriented waste management. Journal of Industrial Ecology 2009;13(1):11-4.

Brunner PH, Rechberger H. Practical handbook of material flow analysis. Boca Raton, FL: CRC/Lewis; 2004.

Campo MD, Bonnet D, Gegenwart R, Hofheim J, inventor; Antec Solar, assignee. Process for recycling CdTe/CdS thin-film solar modules. United States Patent. US 2002/0030035 A12003.

Candelise C, Spiers JF, Gross RJK. Materials availability for thin film (TF) PV technologies development: A real concern? Renewable and Sustainable Energy Reviews 2011;15(9):4972-81.

Cencic O, Rechberger H. Material Flow Analysis with software STAN. Journal of Environmental Engineering and Management 2008;18(1):3-7.

DeFilippo M. End-of-life photovoltaic modules. Golden, USA; 2011.

ECN. Annex $V$ to the report of the ad-hoc working group on defining critical raw materials; 2010.

Elshkaki A, van der Voet E, Timmermans V, van Holderbeke M. Dynamic stock modelling: A method for the identification and estimation of future waste streams and emissions based on past production and product stock characteristics: Dubrovnik Conference on Sustainable Development of Energy, Water and Environment Systems. Energy 2005;30(8):1353-63.

Encore Solar. Technology, 2012. Available from: http://www.encore-solar.com/technology.html [accessed 4/02/2012].

Enzenroth RA, Barth KL, Sampath WS, Manivannan V. Performance of in-line manufactured CdTe thin film photovoltaic devices. Journal of Solar Energy Engineering 2007;129(3):327-30.

EPA. Electronics Waste Management in the United States through 2009; 2011.

EPIA. Solar Generation 6: Solar photovoltaic electricity powering the world; 2011.

European Parliament. Waste electrical and electronic equipment - Texts adopted in the second reading legislative resolution of 19 January 2012., 2012. Available from:

http://www.europarl.europa.eu/sides/getDoc.do?pubRef=-//EP//TEXT+TA+P7-TA-20120009+0+DOC+XML+V0//EN [accessed 25/01/2012].

Feltrin A, Freundlich A. Material considerations for terawatt level deployment of photovoltaics. Renewable Energy 2008;33(2).

First Solar. Annual Report 2008, 2009. Available from: http://files.shareholder.com/downloads/FSLR/1978758492x0x457374/036DD0FC-C93E-47F7-87F5B7AE4109D762/Request-2008_FSLR_Annual_Report.pdf [accessed 19/07/2012].

First Solar. Annual Report 2009, 2010. Available from: http://files.shareholder.com/downloads/FSLR/1978758492x0x457364/41B0F663-25E3-4633-834CF59C23F7EF7A/Request-2009_annual_report.pdf [accessed 19/07/2012].

First Solar. Annual Report 2010, 2011a. Available from: http://investor.firstsolar.com/common/download/download.cfm?companyid=FSLR\&fileid=465411\&filekey =eefec873-ae0b-4e50-8333-eaf7b5d6816d\&filename=Request-FSLR_2011_annual_report.pdf [accessed 28/09/2011]. 
First Solar. Module Collection and Recycling Program, 2011b. Available from:

http://www.firstsolar.com/en/recycle_program.php [accessed 31/10/2011].

First Solar. Quarterly Report for the Period Ending 06/30/12; 2012a.

First Solar. First Solar Sets Another World Record for CdTe Solar PV Efficiency; 2012b.

Fthenakis V. Sustainability of photovoltaics: The case for thin-film solar cells. Renewable and Sustainable Energy Reviews 2009;13(9):2746-50.

Fthenakis VM. Life cycle impact analysis of cadmium in CdTe PV production. Renewable and Sustainable Energy Reviews 2004;8(4):303-34.

Fthenakis VM, Kim HC, Alsema E. Emissions from photovoltaic life cycles. Environmental Science \& Technology 2008;42(6):2168-74.

Fthenakis VM, Wang W. Extraction and separation of Cd and Te from cadmium telluride photovoltaic manufacturing scrap. Progress in Photovoltaics: Research and Applications 2006;14(4):363-371.

Goozner R, Long MO, Drinkard WF, inventor; Drinkard Metalox, Inc., assignee. Recycling of CdTe photovoltaic waste. United States Patent. 59977181999.

Green MA. Consolidation of thin-film photovoltaic technology: the coming decade of opportunity. Progress in Photovoltaics: Research and Applications 2006a;14(5):383-92.

Green MA. Improved estimates for Te and Se availability from $\mathrm{Cu}$ anode slimes and recent price trends. Progress in Photovoltaics: Research and Applications 2006b;14(8):743-51.

Green MA. Estimates of Te and In prices from direct mining of known ores. Progress in Photovoltaics: Research and Applications 2009;17(5):347-59.

Green MA. Learning experience for thin-film solar modules: First Solar, Inc. case study. Progress in Photovoltaics: Research and Applications 2011;19(4):498-500. Available from: http://dx.doi.org/10.1002/pip.1057.

Hering G. Das Jahr des Tigers. Photon 2011;2011(04):38-71.

Huisman J, Magalini F, Artim E, Szlezak J, Ogilvie S, Poll J et al. Review of Directive 2002/96 on Waste Electrical and Electronic Equipment (WEEE): Final Report; 2008.

IEA. Technology Roadmap: Solar photovoltaic energy; 2010.

Johnson NW, Kormanyos KR, Reiter, Nicholas A., inventor; Calyxo GmbH, assignee. Atmospheric pressure chemical vapor deposition. United States Patent. US 7,674,713 B22006.

Jones EW, Barrioz V, Irvine SJC, Lamb D. Towards ultra-thin CdTe solar cells using MOCVD: Thin film chalogenide photovoltaic materials. Thin Solid Films 2009;517(7):2226-30.

Kazmerski L. Best research-cell efficiencies as a function of time for various technologies; 2011.

Kernbaum S. PV module recycling: An alternative approach to recover materials. Madrid, Spain; 2011.

KfW. Anlage zum Kreditantrag KfW-Programm Erneuerbare Energien - Standard (270), 2009. Available from: http://www.kfw-mittelstandsbank.de/DE_Home/Dokumente/PDF-

Dokumente/142461_Anlage_KA_EE_Standard_270_2009_03_ausfuellbar.pdf [accessed 14/09/2010].

Kleijn R, Huele R, van der Voet E. Dynamic substance flow analysis: the delaying mechanism of stocks, with the case of PVC in Sweden. Ecological Economics 2000;32(2):241-54.

Krueger L. Overview of First Solar's module collection and recycling program. Berlin, Germany;2010.

Melo MT. Statistical analysis of metal scrap generation: the case of aluminium in Germany. Resources, Conservation and Recycling 1999;26(2):91-113.

NGI. Environmental risks of CdTe PV modules regarding use and final disposal; 2010.

Ojebuoboh F. Selenium and tellurium from copper refinery slimes and their changing applications. World of Metallurgy - ERZMETALL 2008;61(1):33-9.

Palitzsch W. Waste recovery strategies from Loser Chemie using the example of photovoltaic waste“. Madrid, Spain; 2010.

photovoltaik-Magazin. First Solars Baustelle, 2012. Available from: http://www.photovoltaik.eu/heftarchiv/artikel/beitrag/first-solars-baustelle_100007054/86/?tx_ttnews\%5BbackCat\%5D=203\&cHash=bb848ae2206d934e2bf6b88ac05d5bd2 [accessed 19/07/2012].

pv magazine. Cadmium won't be banned under RoHS, as lobbyists battle it out, 2010. Available from: http://www.pv-magazine.com/news/details/beitrag/cadmium-wont-be-banned-under-rohs--as-lobbyistsbattle-it-out_100001649/ [accessed 20/02/2012].

pv-magazine. Abound Solar to close, 2012a. Available from: http://www.pvmagazine.com/news/details/beitrag/abound-solar-to-close_100007521/ [accessed 6/09/2012].

pv-magazine. GE puts CdTe plant on hold, 2012b. Available from: http://www.pvmagazine.com/news/details/beitrag/ge-puts-cdte-plant-on-hold_100007623/ [accessed 6/09/2012]. 
Raugei M, Fthenakis V. Cadmium flows and emissions from CdTe PV: future expectations. Energy Policy 2010;38(9):5223-8.

Raugei M. Energy pay-back time: methodological caveats and future scenarios. Progess in Photovoltaics: Research and Applications 2012;Epub 12.01.2012

Razykov TM, Ferekides CS, Morel D, Stefanakos E, Ullal HS, Upadhyaya HM. Solar photovoltaic electricity: Current status and future prospects: Progress in Solar Energy. Solar Energy 2011;85(8):1580-608.

Ross M, Rich G, Petacci L, Klammer J. Improvement in reliability and energy yield prediction of thin-film CdS/CdTe PV modules. In: Conference record of the 2006 IEEE 4th World Conference on Photovoltaic Energy Conversion: WCPEC-4 Hilton Waikoloa Village, Waikoloa, Hawaii, 7-12 May 2006. Piscataway: IEEE Xplore; 2007.

Sander K, Schilling S, Reinschmidt J, Wambach K, Schlenker S, Müller A et al. Study on the development of a take back and recovery system for photovoltaic products; 2007.

Suys M. Recycling valuable metals from thin film modules. Berlin, Germany; 2010.

USGS. 2010 Minerals Yearbook: Selenium and Tellurium [Advanced Release]; 2011a.

USGS. Mineral Commodity Summary: Tellurium; 2011b.

Wadia C, Alivisatos AP, Kammen DM. Supporting information for materials availability drives the opportunity for large-scale photovoltaics development; 2008.

Wadia C, Alivisatos AP, Kammen DM. Materials availability expands the opportunity for large-scale photovoltaics deployment. Environmental Science and Technology 2009;43(6):2072-7.

Zuser A, Rechberger H. Considerations of resource availability in technology development strategies: The case study of photovoltaics. Resources, Conservation and Recycling 2011;56(1):56-65.

Zweibel K. Issues in thin film PV manufacturing cost reduction. Solar Energy Materials and Solar Cells 1999;59(1-2):1-18.

Zweibel K. The impact of tellurium supply on cadmium telluride photovoltaics. Science 2010;328(5979):699701. 